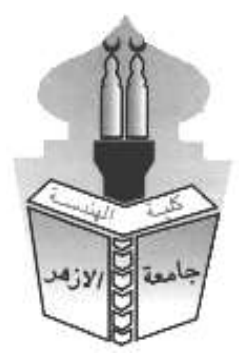

\title{
APPLICATIONS OF SMART TECHNOLOGIES IN BUILDINGS AND THEIR ROLE IN ACHIEVING SUSTAINABLE ARCHITECTURE
}

\author{
Fouad Abd Almagoud Abd Alhaleem*1, Abbas Mahmoud Abbas ${ }^{1}$ And Mostafa Bogdady \\ ${ }^{1}$ Architecture Engineering Department, Faculty of Eng., Al- Azhar University, Qena, Egypt. \\ ${ }^{2}$ Architecture Engineering Department, Faculty Of Eng., Al- Azhar University, Cairo, Egypt. \\ *Corresponding Author E-mail: fouadqasim@azhar.edu.eg
}

\begin{abstract}
The research study focused on the importance of integrating smart technologies used in buildings with the principles of sustainable architecture under environmental considerations and determinants to reach a sustainable smart building. Its idea is summarized in the extent to which the smart building is environmentally compatible through the merging and integration between smart technologies and environmental standards that are compatible with sustainability, which achieve the efficiency of the internal environment of the building through rationalization of energy consumption, the exploitation of renewable energy sources and the possibility of collecting environmental data, which called many countries of the world to apply The right thing for smart buildings compatible with sustainability. The importance of the study, which aims to shed light on the role of technologies and smart systems in buildings, in achieving the principles of sustainable architecture, by clarifying the concepts, characteristics and systems of smart buildings, in addition to reviewing the concepts and principles of sustainable architecture and clarifying the elements and determinants of their achievement.
\end{abstract}

KEY WORDS: Smart Building, Smart System, Automation, Responsive, Sustainable Architecture.

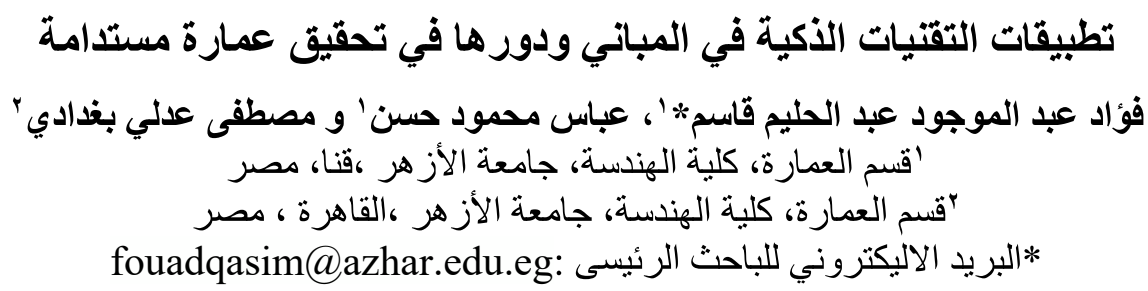

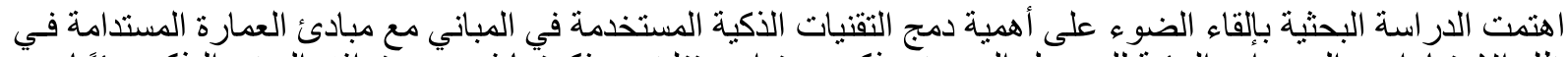

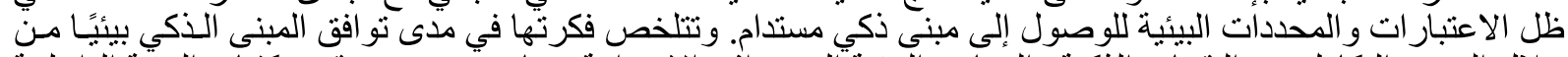

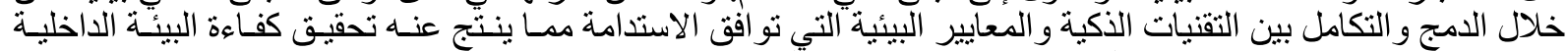

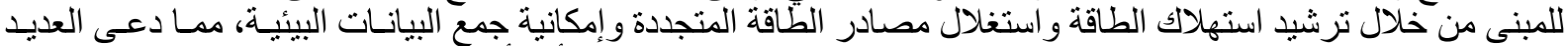

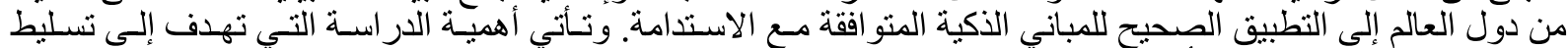

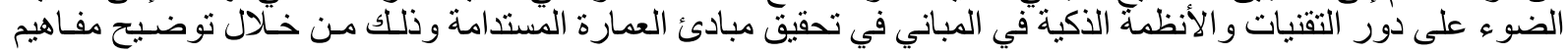


وسمات و أنظمة المباني الذكية بالإضافة إلى استعر اض مفـاهيم ومبـادئ العمـارة المستدامة وتوضيح عناصـر ومحددات تحقيقها. وقد خلصنت الدر اسة إلى إعداد قائمة بالمعايير و المحددات التكنولوجية و البيئية (مقترح بحثي) الو اجب اتباعها عند تصميم

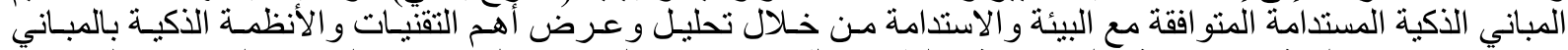

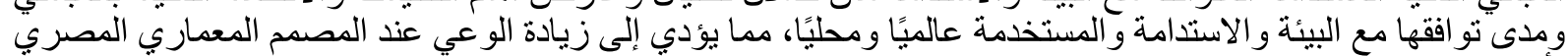

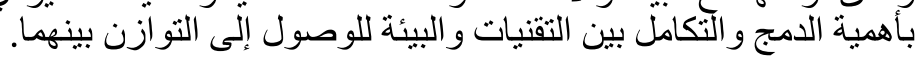

الكلمات المفتاحية: المباني الأكية ، الأنظمة الذكية ، الأتمتة ، الاستجابة ، العمارة المستدامة .

مقدمة:

يهتم المصدم المعماري بخصائص ومحددات الأنظمة و التقنيات الذكيـة لتحقيق المتطلبـات التصميمية حيث أنها التها من أكثر

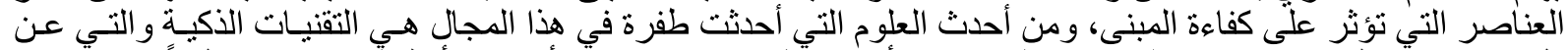

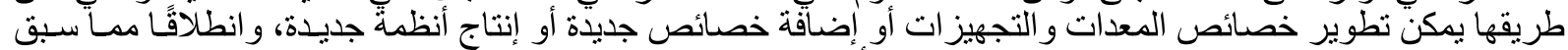

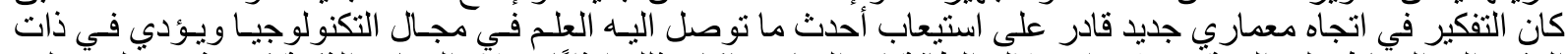

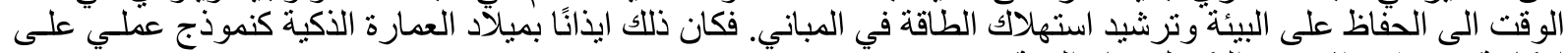
امكانية حدوث تو افق بين التنكنولوجيا و البيئة.

\section{الاشكالية البحثية:}

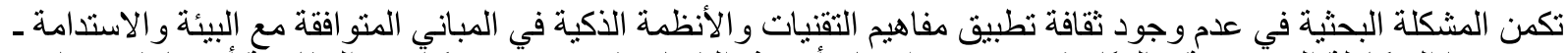

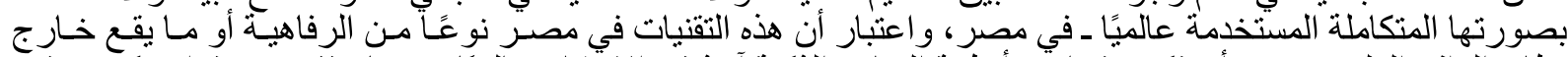

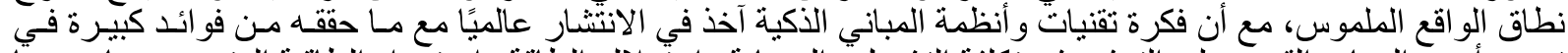

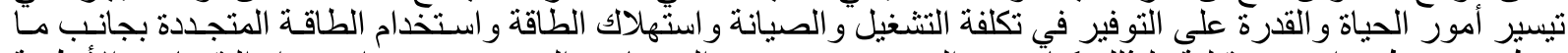

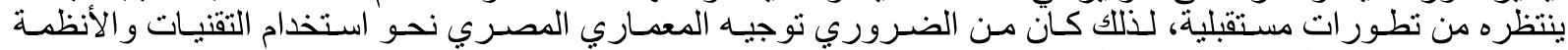
التكنولوجية الحديثة للمباني الذكية و التي بدور ها تقوم بتحقيق التو افق مع البيئة والاستدامةً.

أهداف البحث:

تحاول الدر اسة البحثية استخدام امكانيات التقنيات الذكية في المباني لتحقيق مبادئ العمارة المستدامة وذلك من خلال:

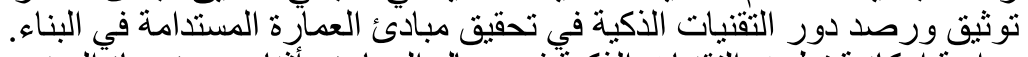

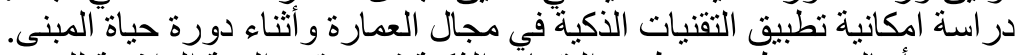
توضيح أساليب نوظيف ونظيق وتطبيق التقنيات الذكية في تحقيق البيئة الملائمة للمبنى.

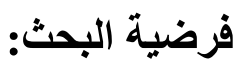

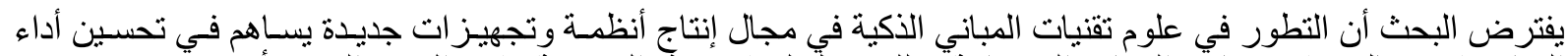

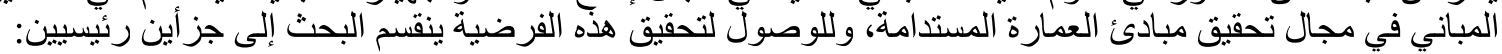

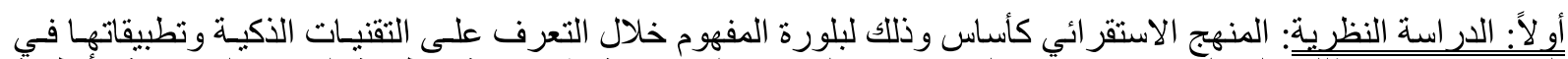

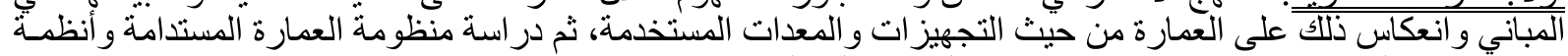

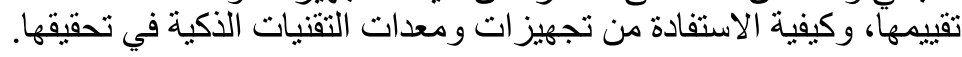

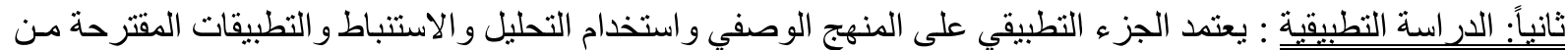

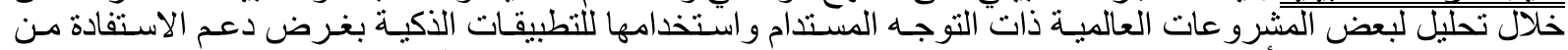

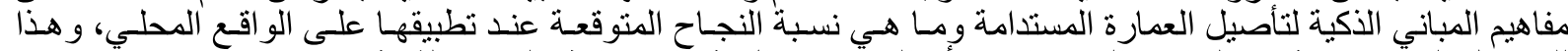

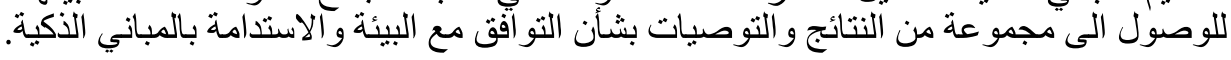

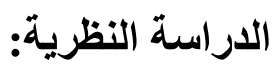

1/المباني الأكية:

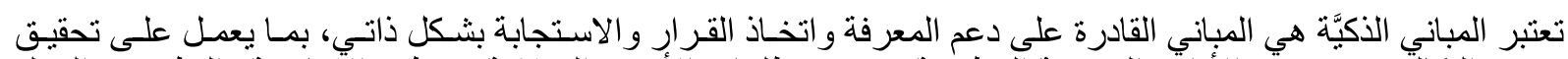

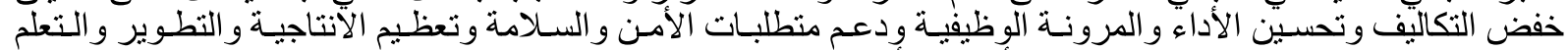

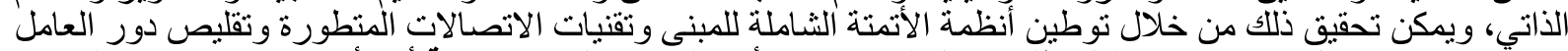

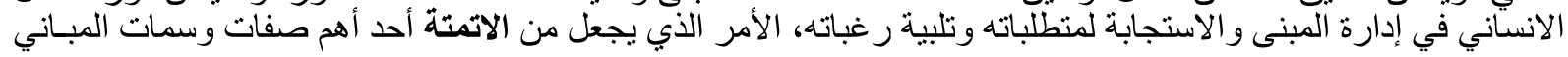


الذكيَّة، وفقاً لمجموعة كبيرة من الرؤى والاطروحات، وتعتبر الأتمنة أول المداخل التي يمكن من خلالها الوصول إلى منتج معماري ذكي [11.

1/1/1/ نبذة تاريخية لنشأة و تطور فكرة المبانى الذكية:

من خلال در اسة التطور التاريخى للمبانى الذكية منذ بداية ظهور ها في الو لايات المتحدة الامريكية فى أو ائل الثمانينات حتى

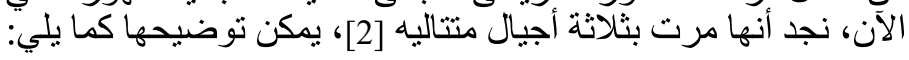

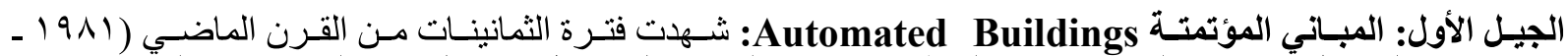

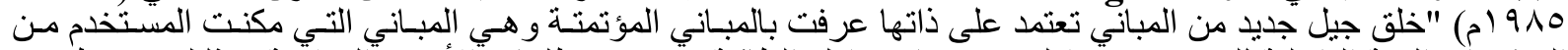

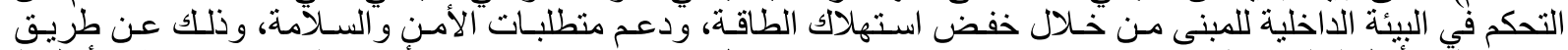

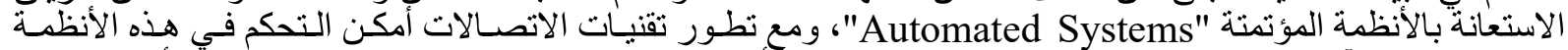

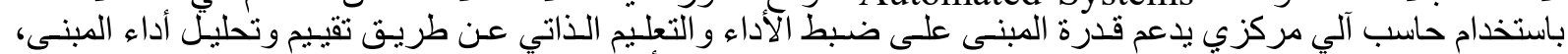

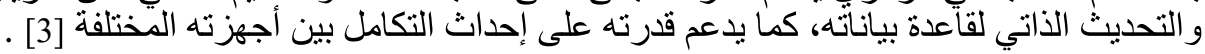

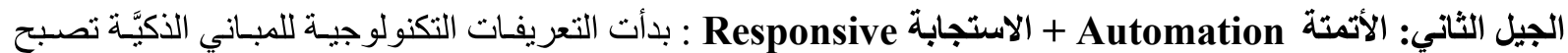

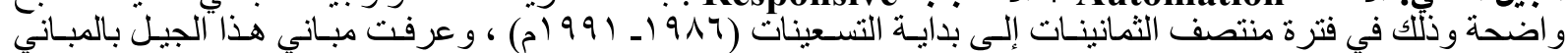

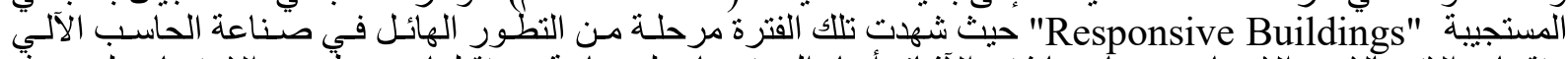

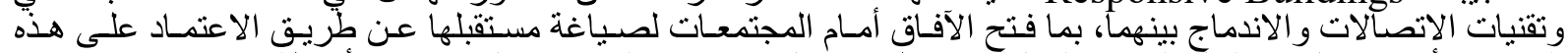

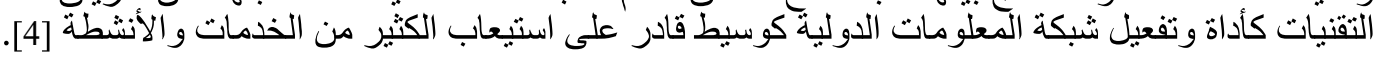

(الجيل الثالث:الأتمتة Automation + الاستجابة Eesponsive + الفاعلية Effective : شهدت نهاية القرن العشرين

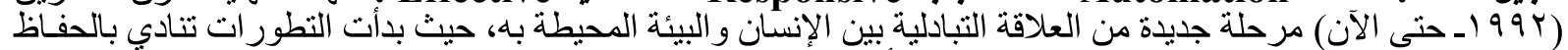

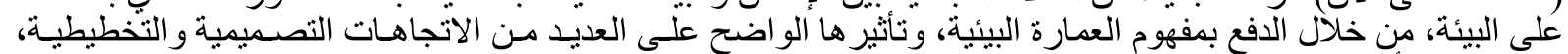

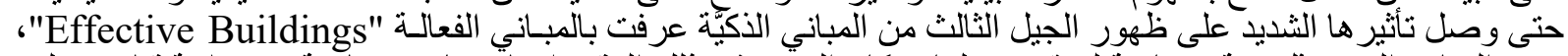

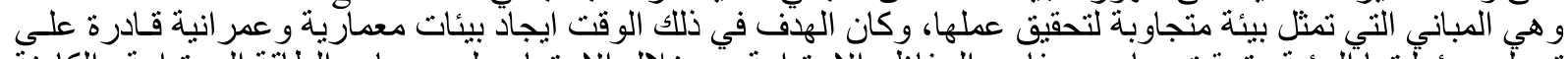

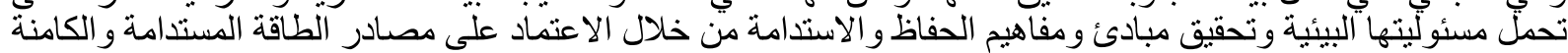

وغير الملوثة للبيئة [5].

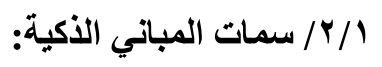

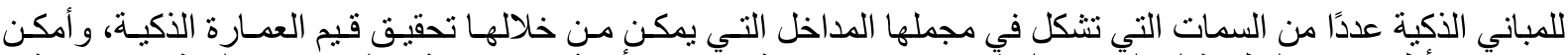
تصنيفِ الأطروحات النظرية لها لتقع داخل ثُلاث سمات رئيسية وهي : الأتمتة ـ الاستجابة ــ التوافق مع البيئة و الاستدامة.

الأتمتـة Automation: ظهـر مفهوم الأتمتـة أو أنظمـة أتمتـة المبنى (Building Automation Systems BAS)،

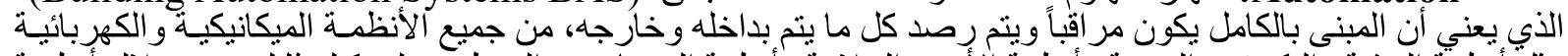

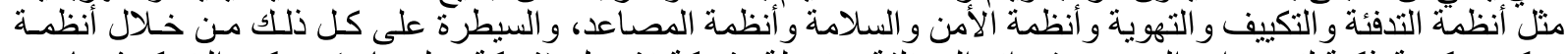

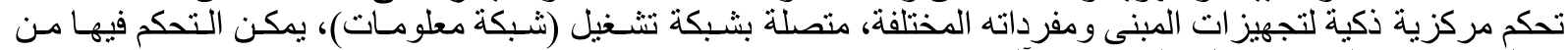
خلال برنامج معلوماتي يعمل على عاتى حاسب آلي [6].

الاستجابة Responsive: المقصود باستجابة المبنى قدرة المبنى على تلبية رغبات ومتطلبات شاغليه وللتغير ات في البيئة

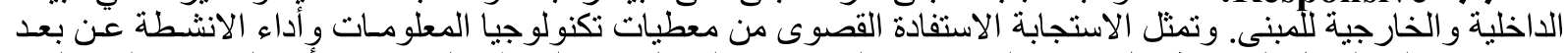

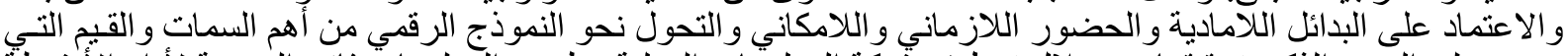

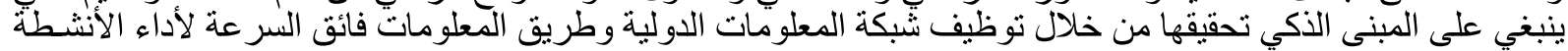
واستغلال التكنولوجيا الزرقمية المتاحة [1] [7].

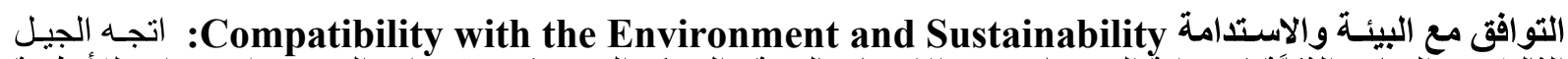

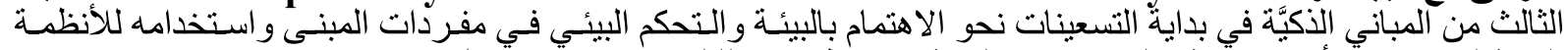

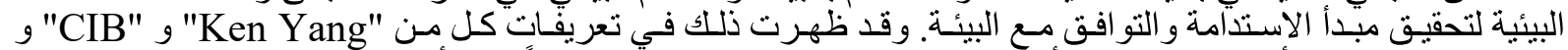

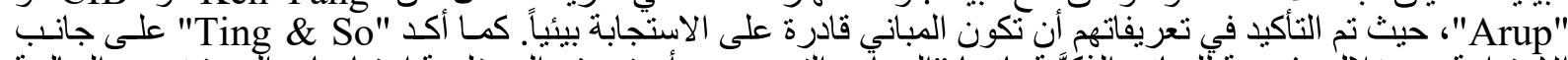

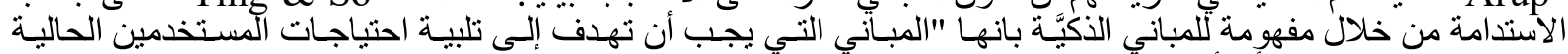
و المستقبلية"، وهذا المبدأ الأساسي "التي تقوم عليه فكرة الآستدامة [8 ] ـ

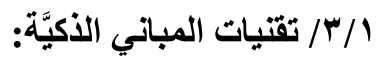

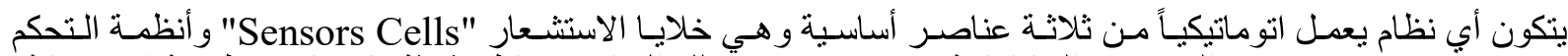

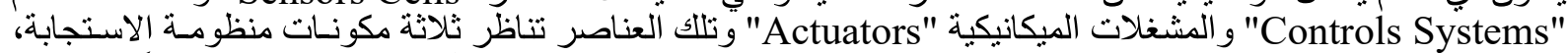

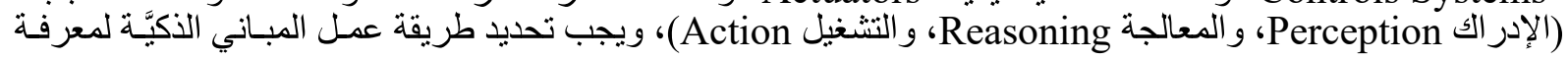


أوجه التشابه والاختلاف عن المباني التقليدية الحديثة، فهناك بعض المعايير الأساسية التي يجب تو افر ها في المباني الحديثة

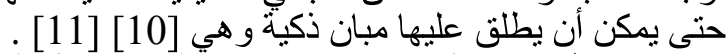

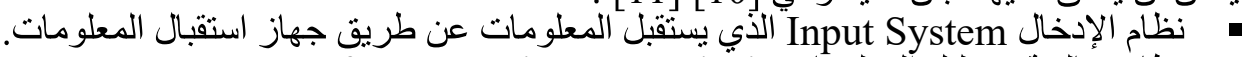

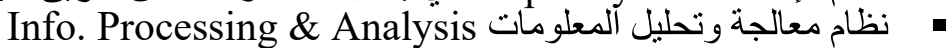

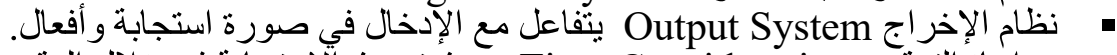

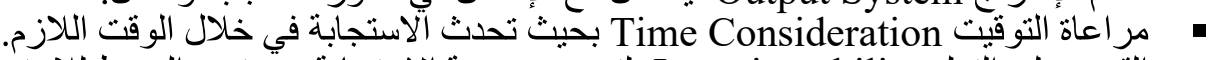
• القدرة على التعلم Learning ability لتحسين سرعة الاستجابة ومستوى الضبط للاستجابة.

أنظمة إدارة المبني Building Management Systems (BMS) تعتبر هذه الأنظمة بمثابة العقل البشري بالنسبة

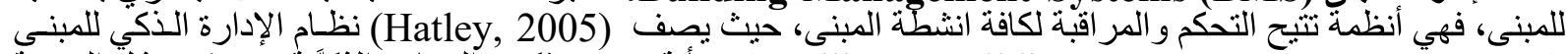
(Intelligent Building Management System IBMS)

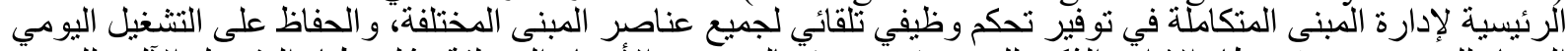

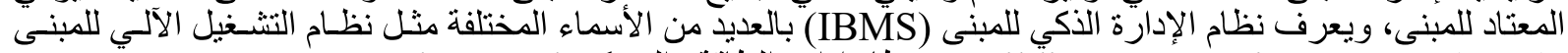
Energy Management and Control Building Automation System (BAS)

(13] [12] Fystem (FMCs) ونظام إدارة المر افق SyS) (FMS)

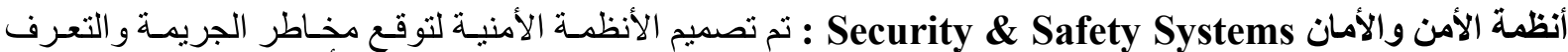

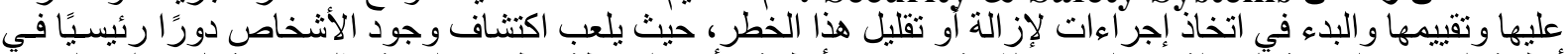

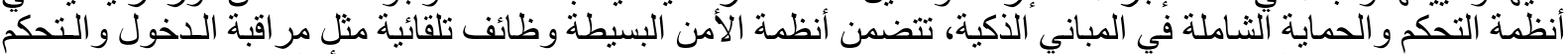

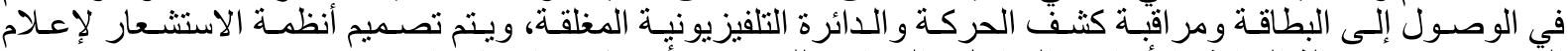

المستخدمين عن حالة النو افذو والأبو اب و المداخل و المخارج للمبنى في أبي وقت لاكتثأف الاختر أق [12].

أنظمة التحكم في إدارة الطاقة: Energy Management Control Systems (EMCS): هي طريقة مخصصـة

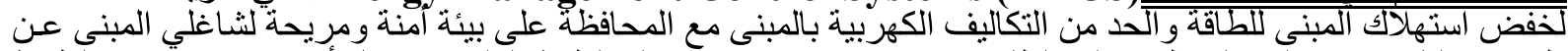

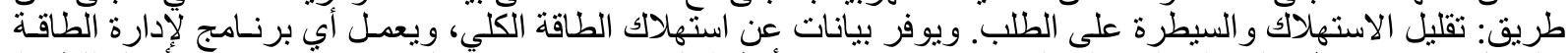

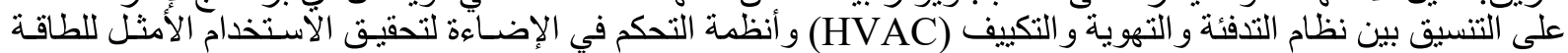

أنظمة التحكم في عناصر المناخ: للتعامل والتحكم في عناصر المناخ سواء داخل الماءل المباني أو المحيط بها، حيث تعتبر الحماية

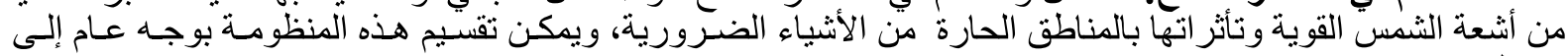
مرحلتين:

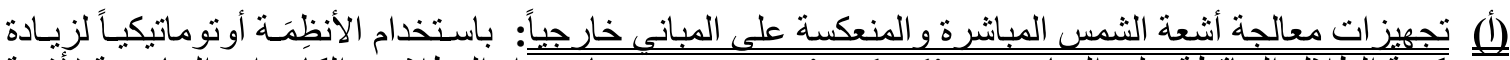

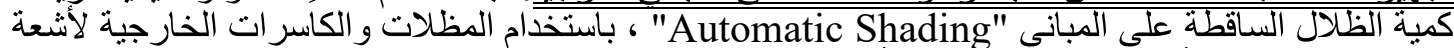

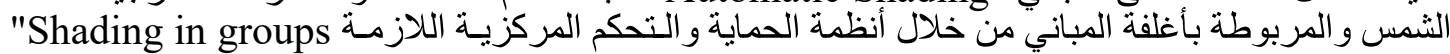
. [14] and centrally controlled"

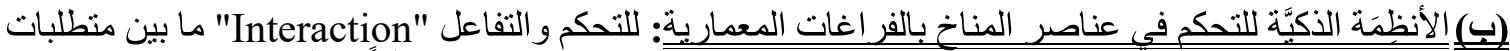

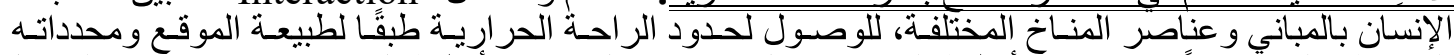

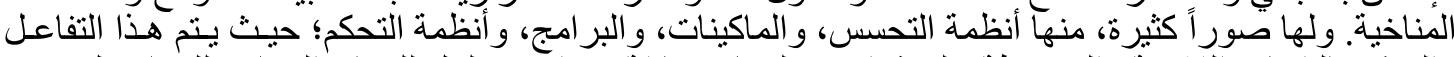

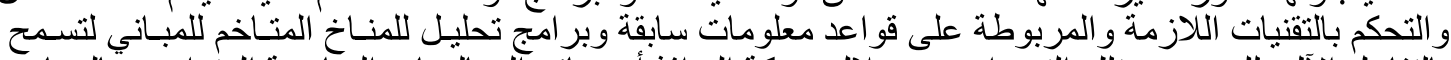

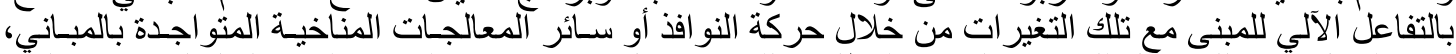

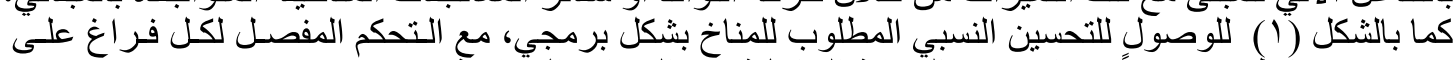

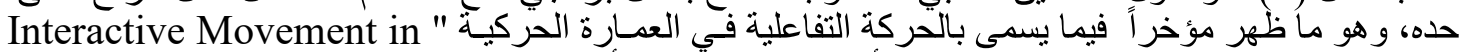

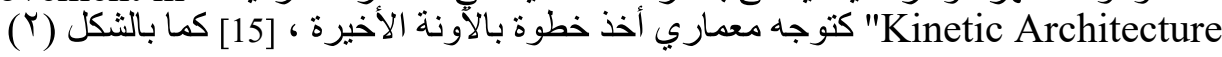




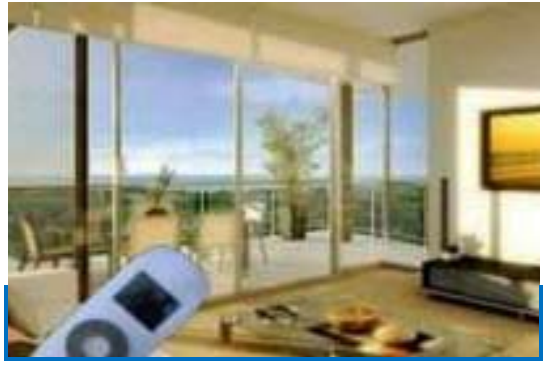

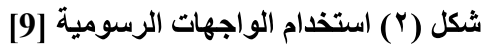

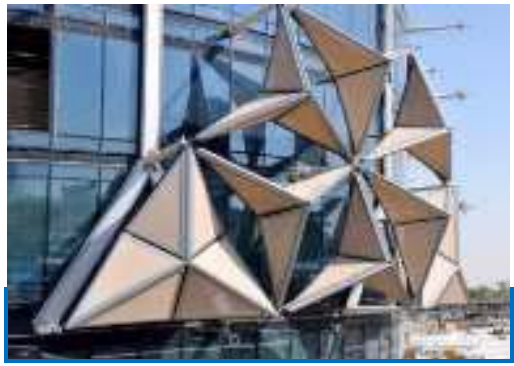

شكل (1) التحكم الأكي بكاسرات اشعة الشمس [9]

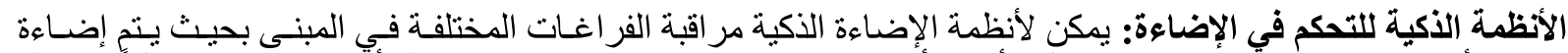

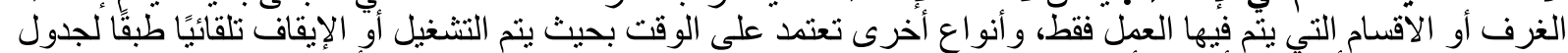

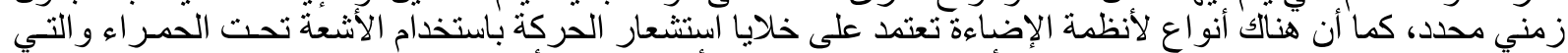

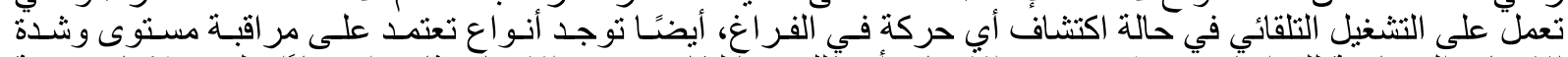

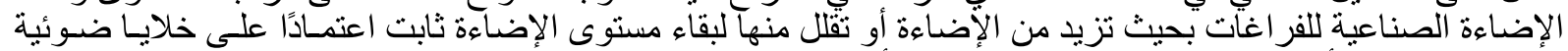

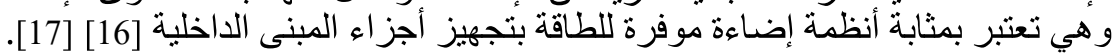

أنظمـة الاتصـالات Communication systems : تتــوع قنـوات الاتصـالات "Communications Channels"

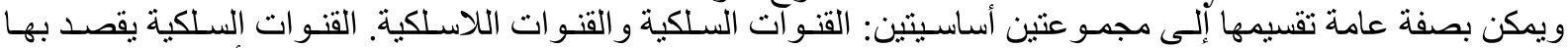

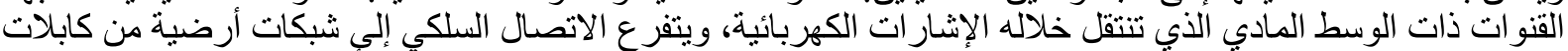

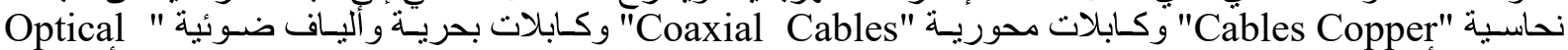

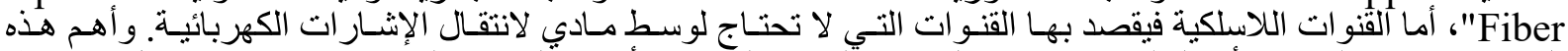

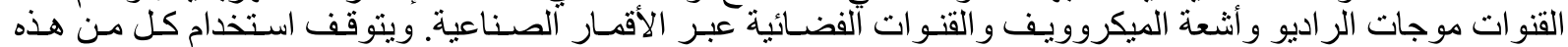

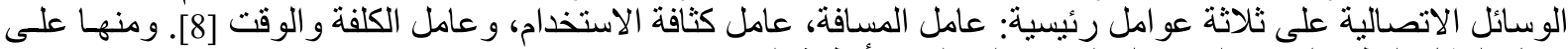

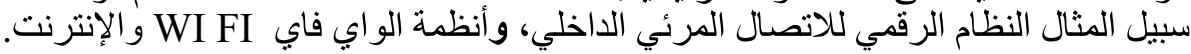

تقتيات المواد الأكية: يتضح أن تطبيقات تقنيات المباني الذكية في المجـال المعدساري تعتمد على الامكانـات الكامنـة داخل

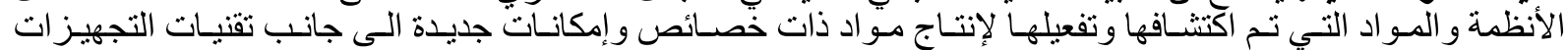

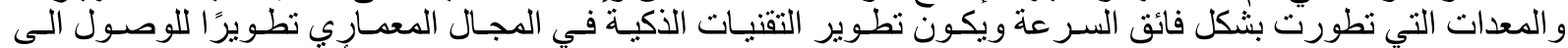

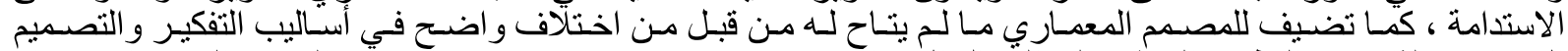

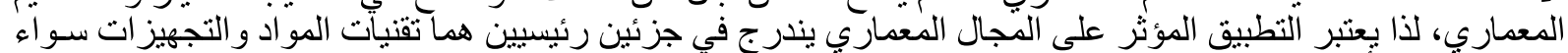

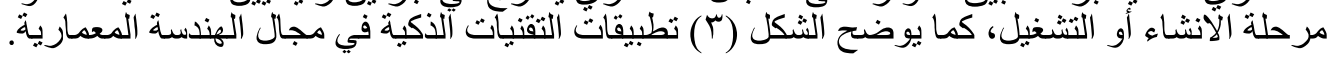

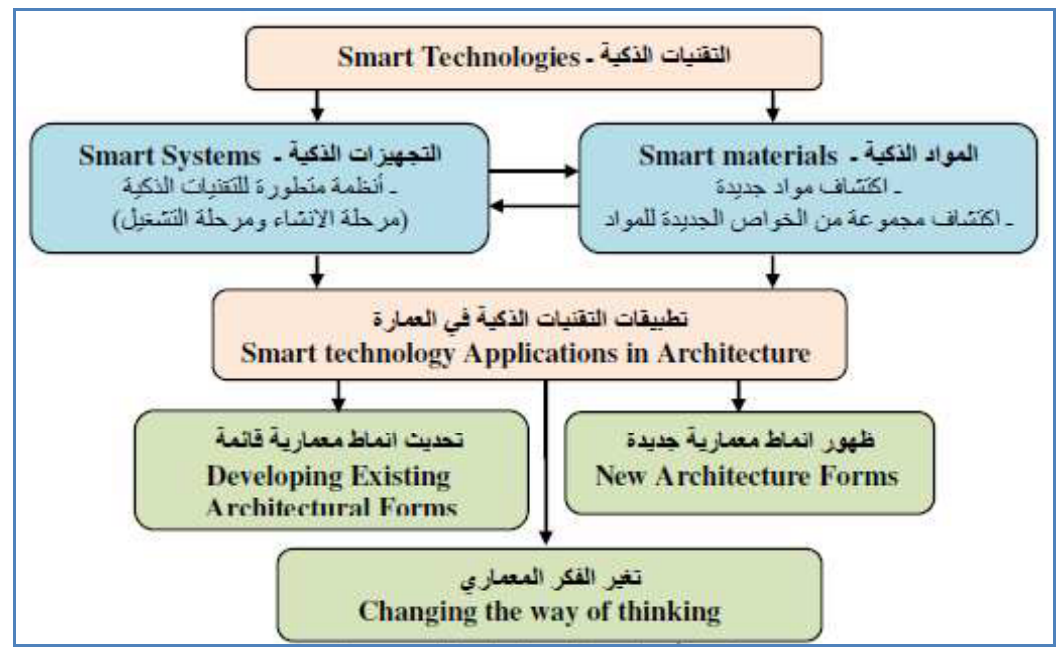

شكل (r) تأثير التقنيات الأكية على المجال المعماري ـ الباحث 


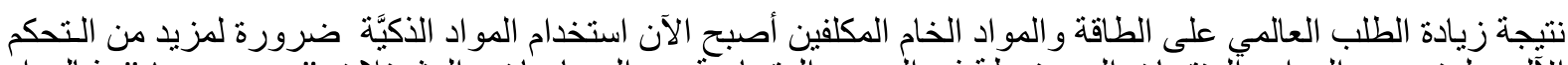

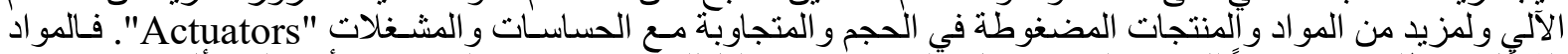

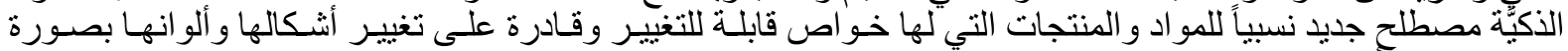

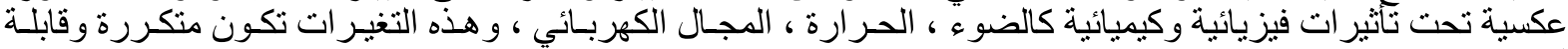

للانعكاس [10]

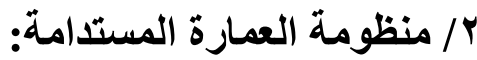

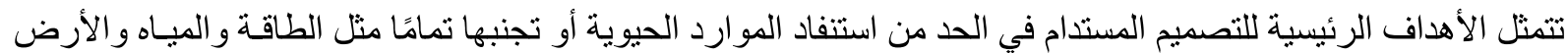

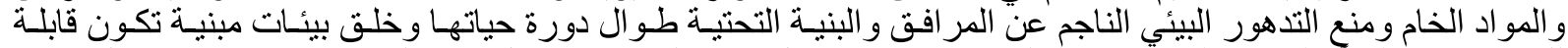

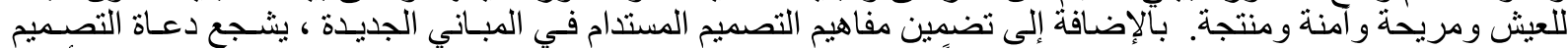

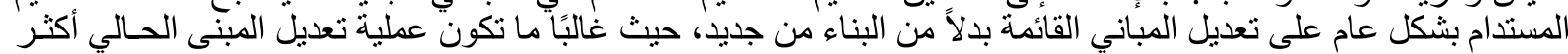

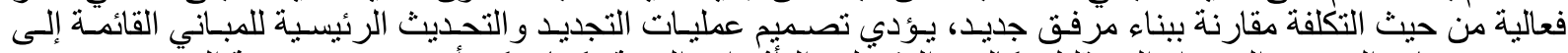

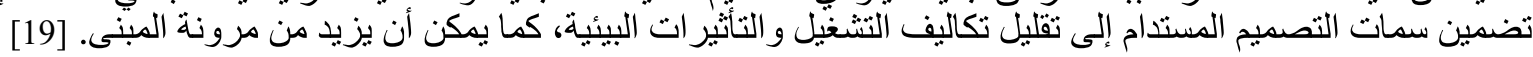

r/ / أنظمة تقييم المباني المستدامة:

يوجد العديد من أنظمة تقييم المباني المستدامة سو اءه على المستوى العالمي أو الاقليمي أو المحلي و التي تضـع الاشتـر اطات

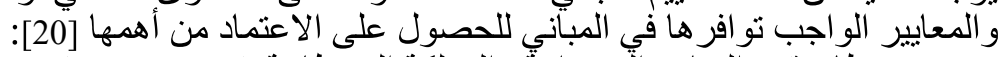

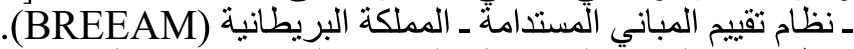
ـ نظام تقييم المباني المستدامة ـ الولايات المبتية المتحدة الامريكية (LEEDTM). ـ نظام تقييم البناني الخضر اءع الدولية ـ الو لايات المتحدة (Green Globes). ـ ـنظام تقييم المباني المستدامة ـ اليابان (CASBEE).

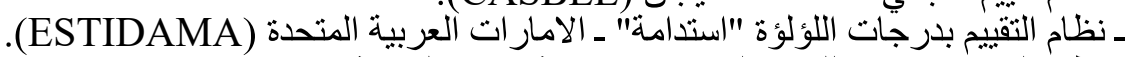
ـ نظام الهرم الاخضر للتقييم البيئي ـ جمهورية مصر العربية (GPRS).

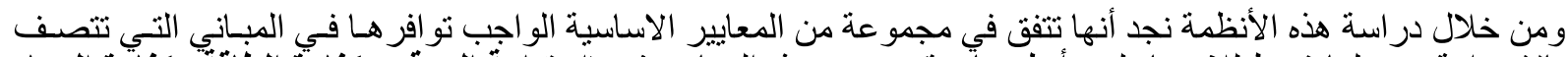

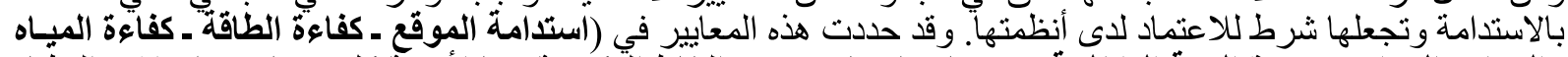

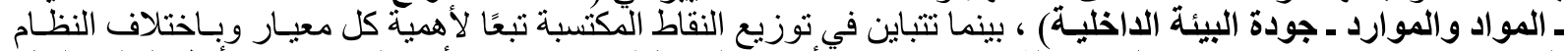

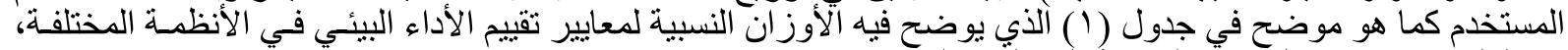
مع العلم توجد بعض المعاييز الفرعية المختلفت عليها.

جدول (1) متوسط الأوزان النسبية لأنظمة تقييم الاداء البيئي [20]

\begin{tabular}{|c|c|c|c|c|c|}
\hline جودة البيئة & المواد والموارد & كفاءة المياه & كفاعة الطاقة & استدامة الموقع & أنظمة تقييم الاداء \\
\hline$\% 15$ & $\% 12.5$ & $\% 6$ & $\% 19$ & $\% 10$ & BREEM \\
\hline$\% 22$ & $\% 19$ & $\% 7$ & $\% 25$ & $\% 20$ & LEED \\
\hline$\% 20$ & $\% 10$ & $\% 8.5$ & $\% 38$ & $\% 11.5$ & Green Globe \\
\hline$\% 20$ & $\% 15$ & $\% 2$ & $\% 20$ & $\% 15$ & CASBEE \\
\hline$\% 21$ & $\% 16$ & $\% 24.2$ & $\% 24.8$ & $\% 6.7$ & ESTIDAMA \\
\hline$\% 10$ & $\% 10$ & $\% 35$ & $\% 25$ & $\% 5$ & GPRS \\
\hline$\% 18$ & $\% 14$ & $\% 14$ & $\% 25$ & $\% 11.5$ & متوسط الأنظمة \\
\hline
\end{tabular}

الاراسة التحليلية:

\section{ب/ م منهجية تحقيق محددات منظومة العمارة المستدامة من خلال تطبيقات التقتيات الذكية:}

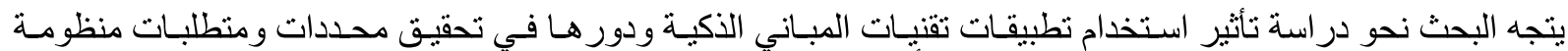

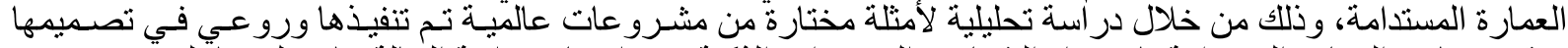

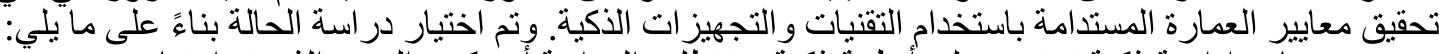

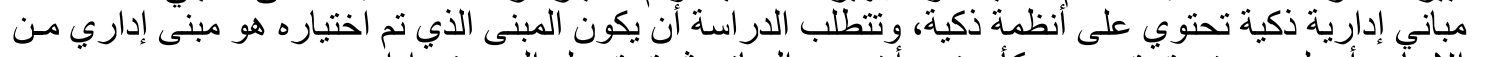

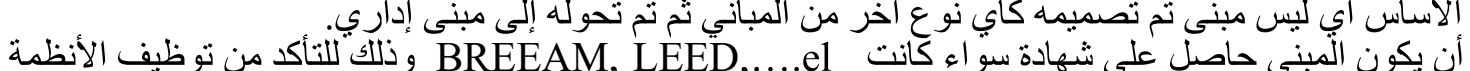
الذكية في معايير الاستدامة. 


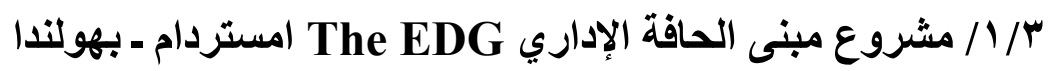

يقع المبنى في منطقة الأعمال "Zuidas Business District" في مدينة أمستردام وقد تـم تصـيم المبنى ليكون مقرا

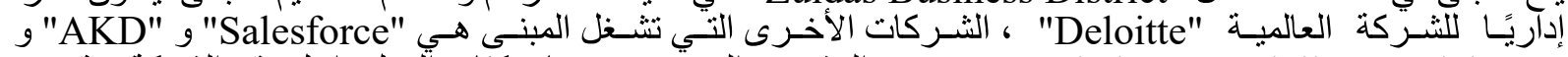

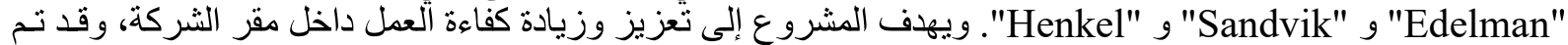

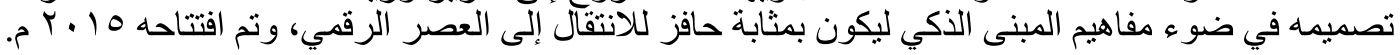

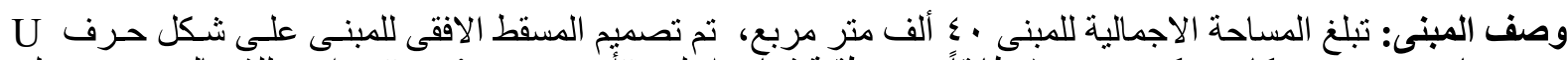

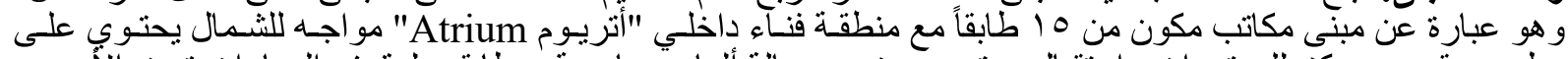

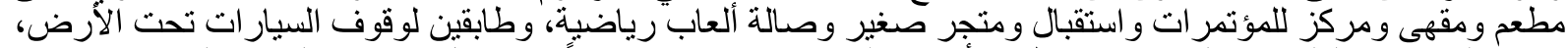

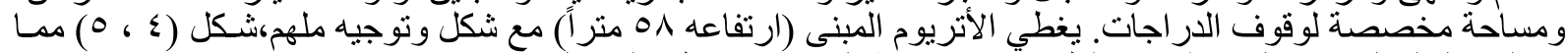
يجعل بيئة العمل مفتوحة مع الضوء الطبيعي، وهي بمثابة جز ألثن من نظام التهوية.

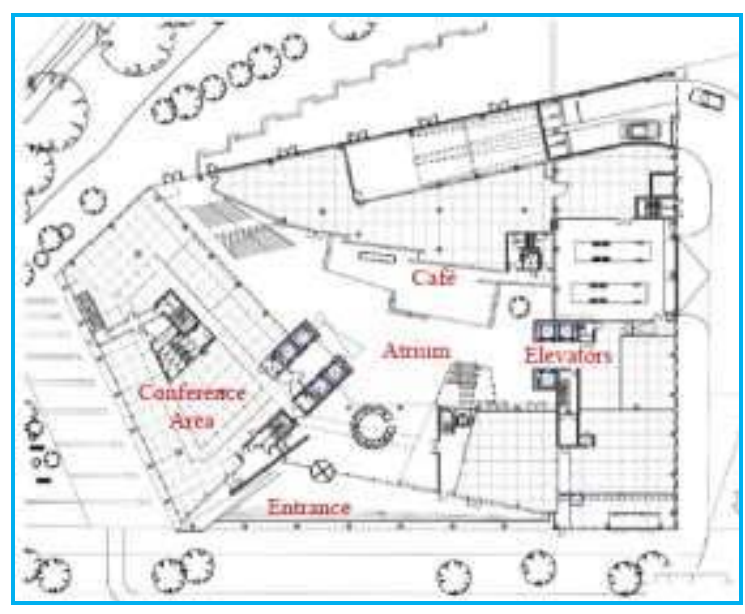

شكل (0) المسقط الافقي للاور الارض للمبنى [24]

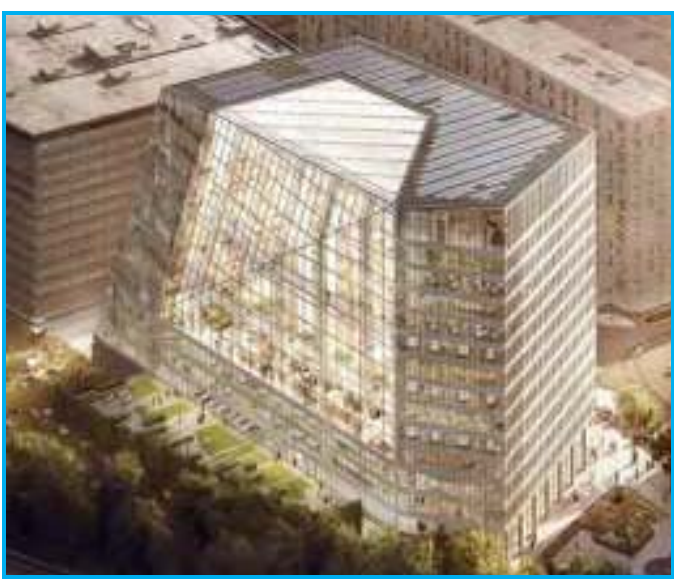

[23] The Edge شكل (؛) يوضح الثكل الخارجي لمبنى

\section{سمات الأكاء بالمبنى}

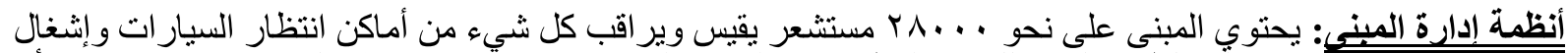

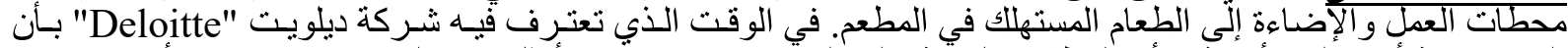

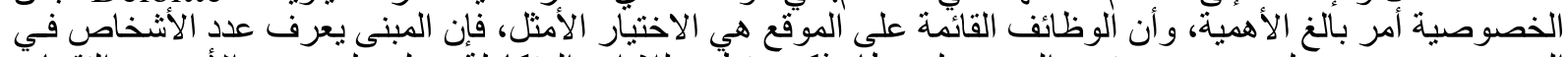

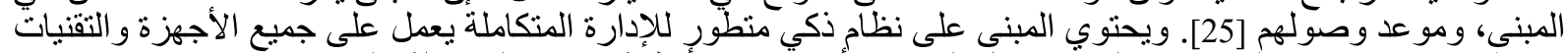

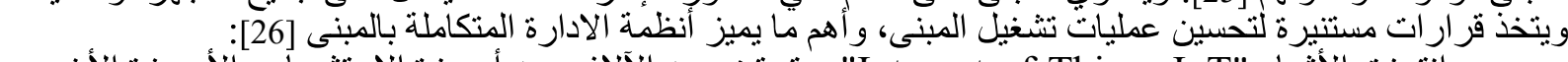

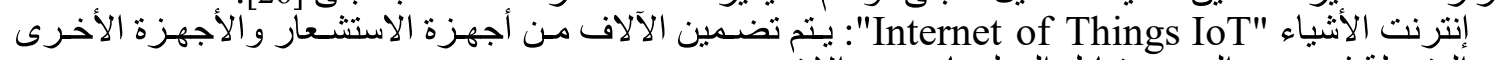

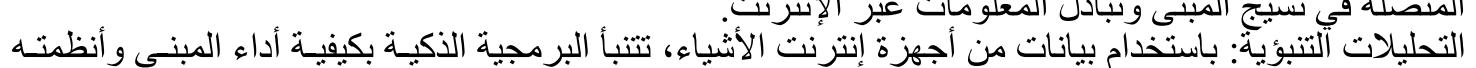

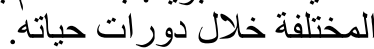

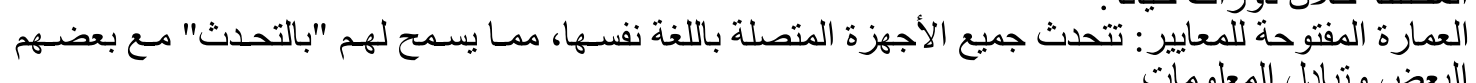
البعض وتبادل المعلومات.

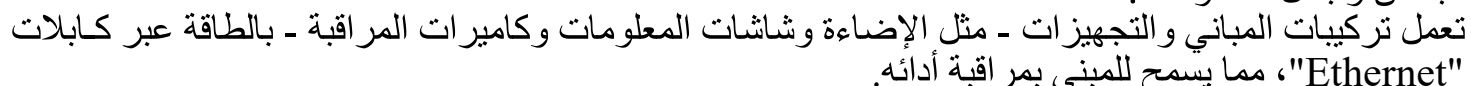

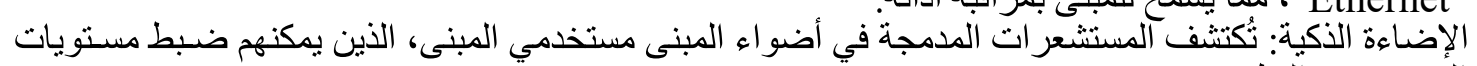
الضوء عبر التطبيق.

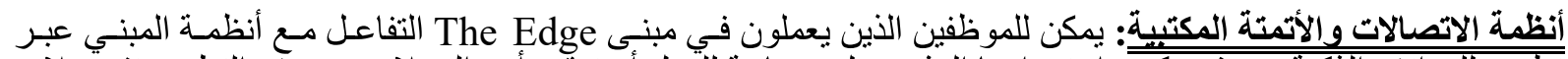

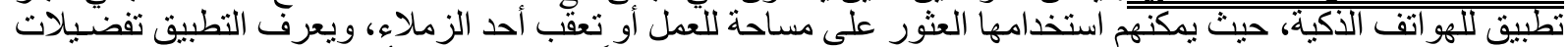
الإضـاءة والحر ارة لمستخدمي المباني الفردية، مما يسمح لله بتعديل البيئة وفقًا لذلك. بالنسبة لأولئك الذين يقودون سيار اتهم 
فإن الدخول إلى موقف السيارات الموظف يكون آليًَا: عند وصولهم ، تلتقط الكامير ا صورة لوحسة ترخيصـهم، وتطابقها مـع سجل عمهه ، وترفع بو ابة المدخل [26].

وعلى الرغم من أن الوصول إلى البيانات للتعرف على الوجه ولوحة الترخيص ينطلب وجود رابط خـارجي، إلا أن معظم

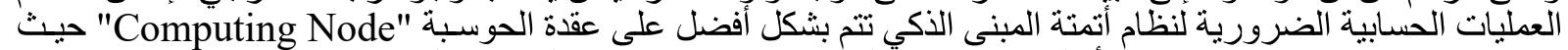

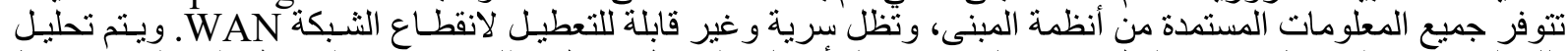

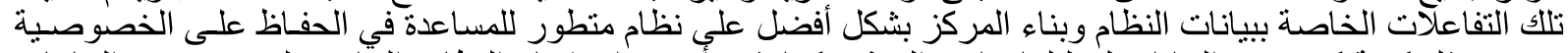

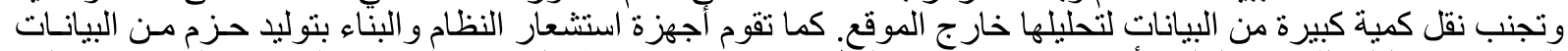

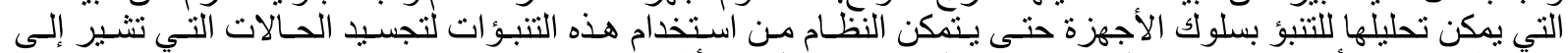
المشّاكل الوشيكة أو التحكم في النظام لتحقيق نقاط التحديد المطلوبة بأقل تكلفة [26].

\section{الاستجابة:}

\section{الاستجابة للمتغيرات في البيئة الاخلية والخارجية:}

ما يميز المبنى قدرته على التعلم، فالمبنى يعمل كعقل بشرى يترجم الظو اهر و المو اقف ويتعامل معها لما هو ملائم لها.

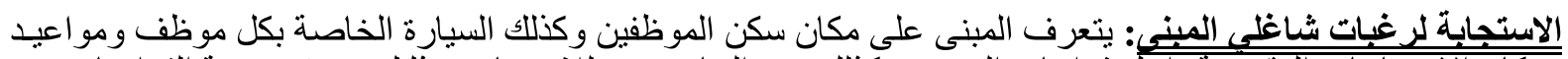

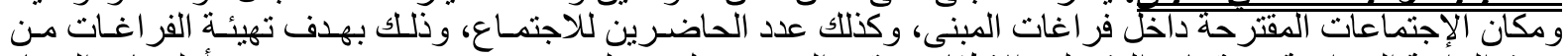

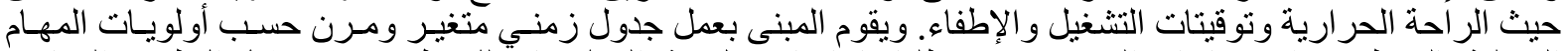

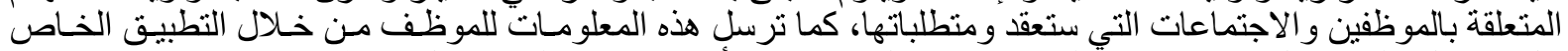

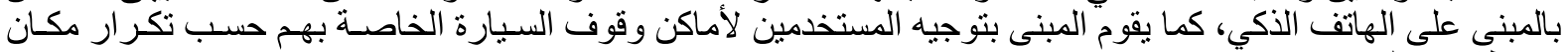

الانتظار بشكل يومي [1]

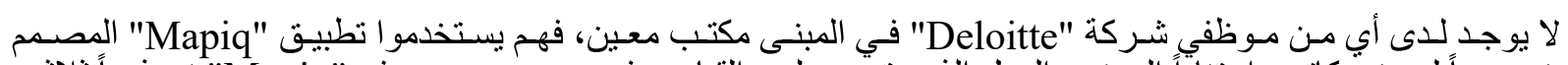

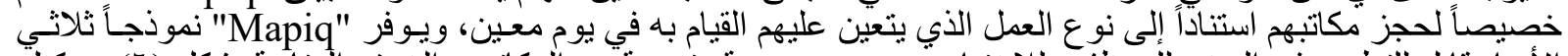

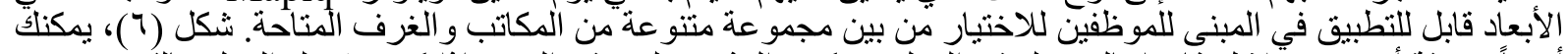

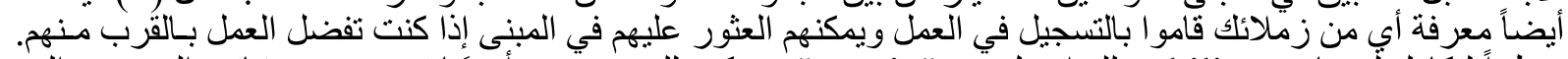

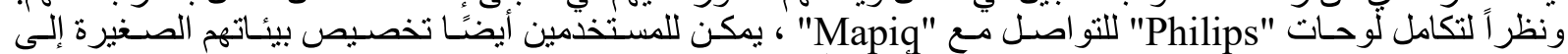

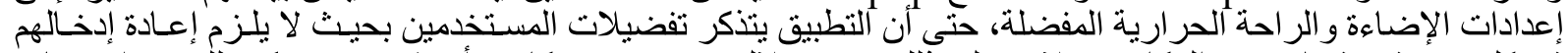

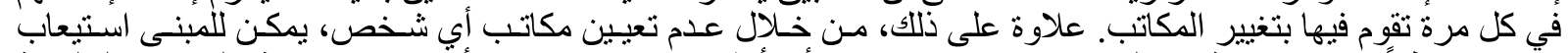

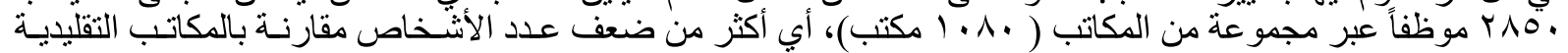
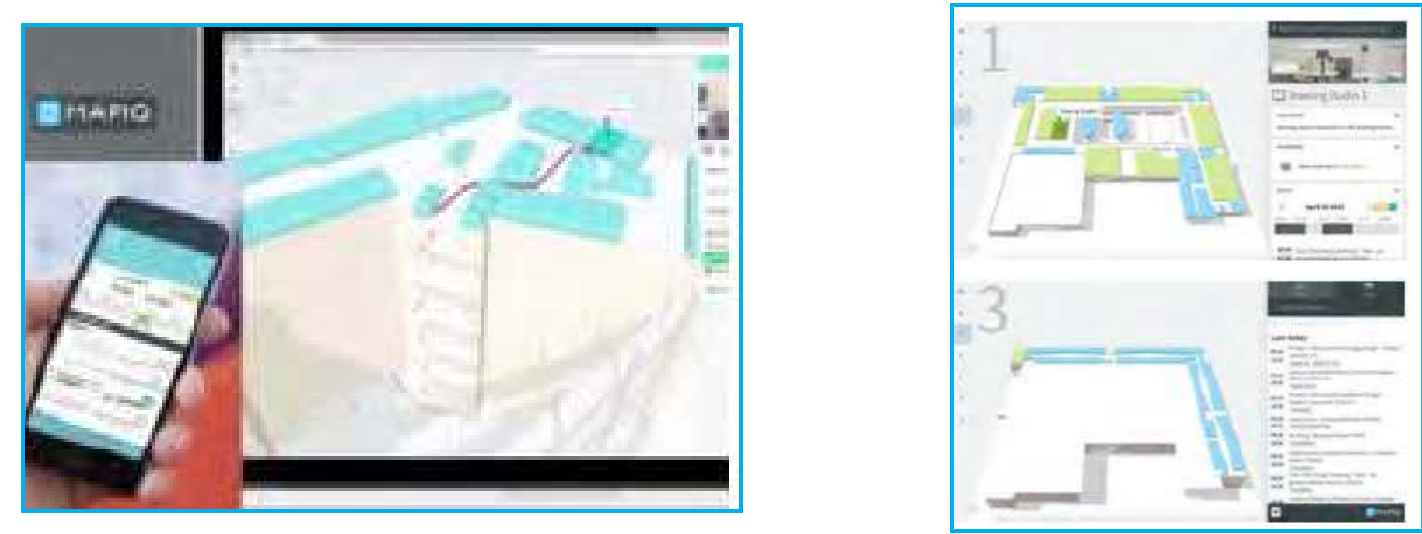

شكل (؟) تطبيق Mapiq حجوزات الإشغال والغرف عبر طوابق مختلفة متراكبة على نموذج ثلاثي الأبعاد [23]

\section{التوافق مع البيئة والاستدامة:}

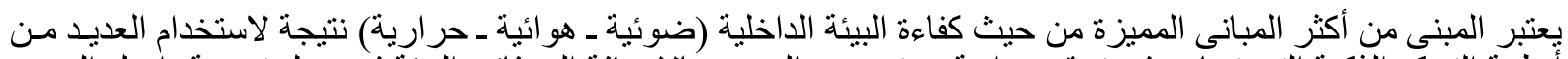

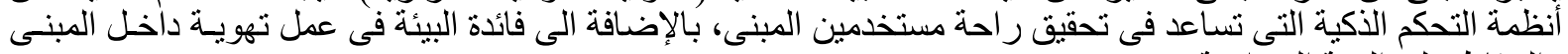




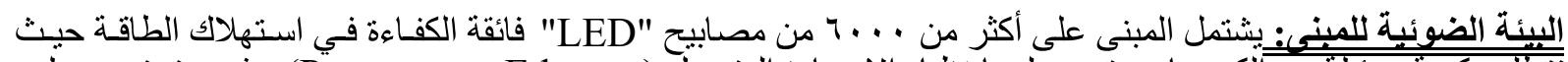

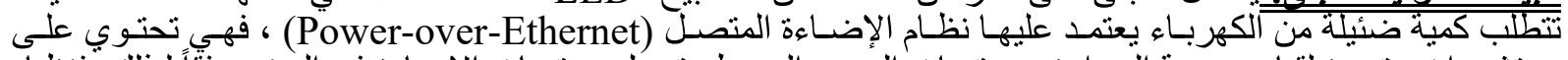

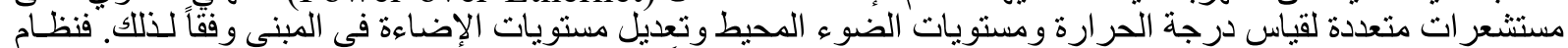

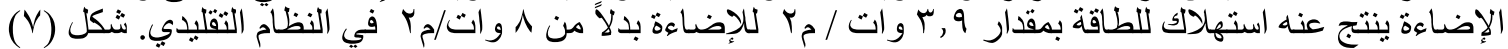

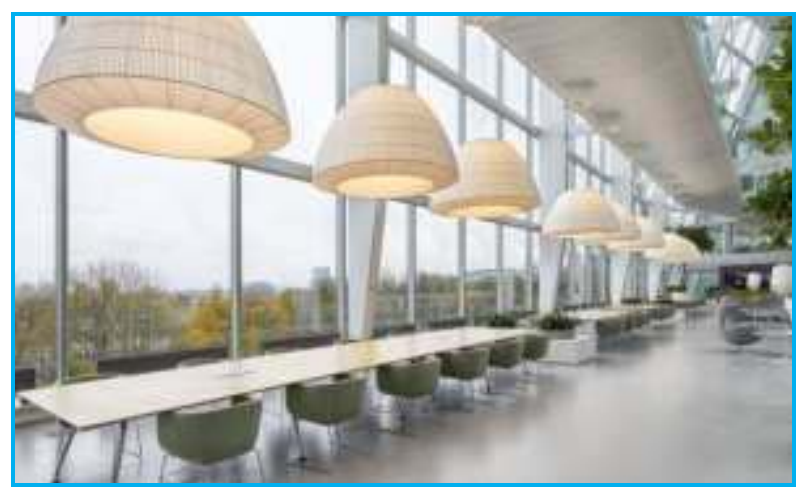

شكل (^) دمج أنظمة الاضاءة الطبيعية والاضاءة الصناعية بالمبنى [27]

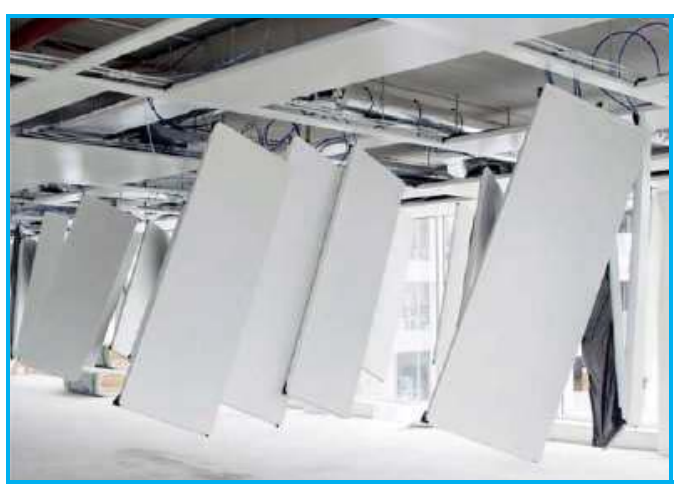

شكل (V) أنظمة الاضاءة المستخدمة في المبنى كابلات الايثرنت خلف السقف المستعار بالمبنى [27 الميني

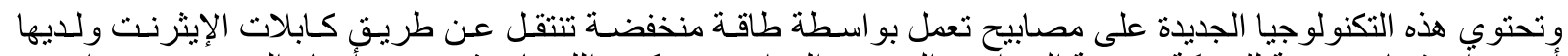

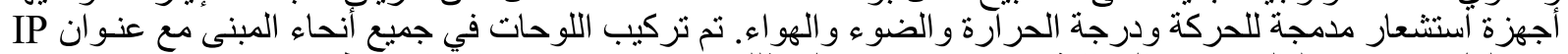

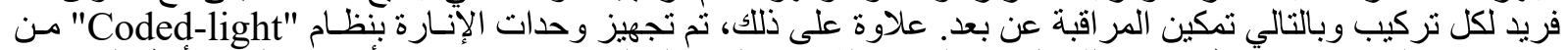

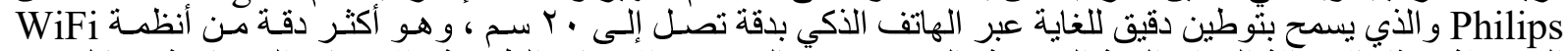

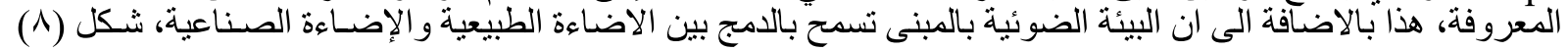

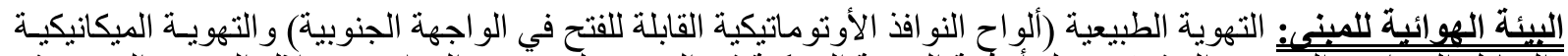

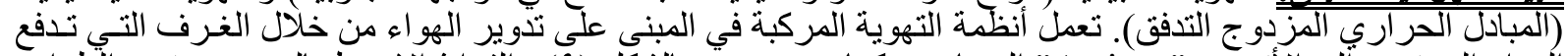

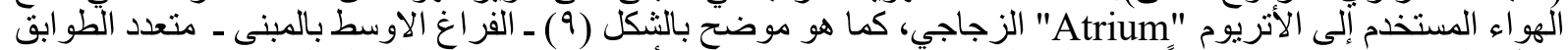

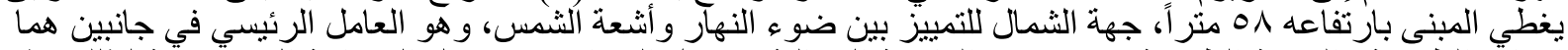

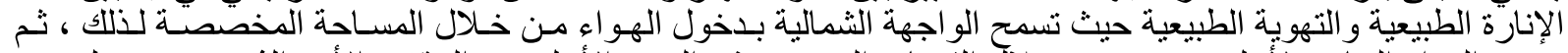

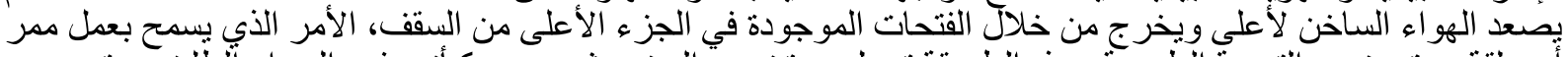

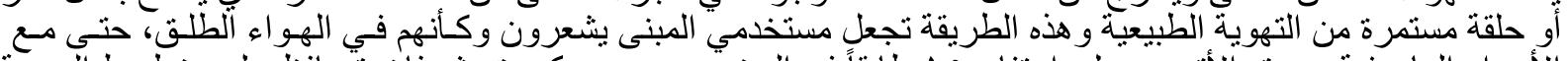

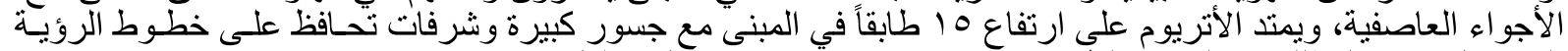

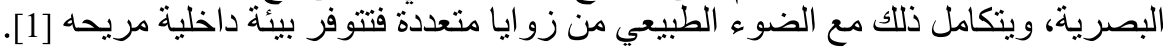
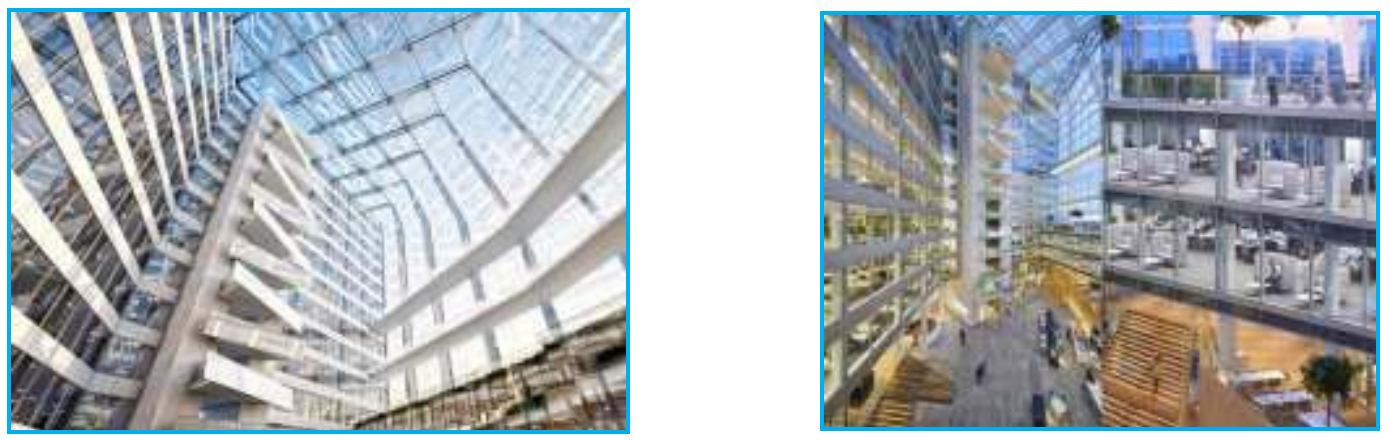

شكل (9) يتميز هذا الأتريوم المكون من 10 طابقًا بنواقذ هائلة ومفمور بالضوء الطبيعي [28]

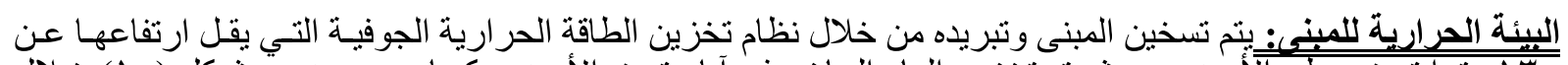

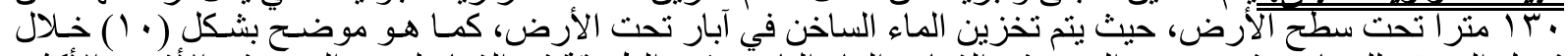
فصل الصيف للمساعدة في تشخين المبنى في الثتاء و الماء البارد بنفس الطريقة في الثناء لتبريد المبنى في الأثـهر الأكثر 


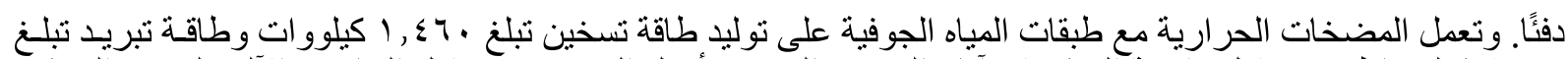

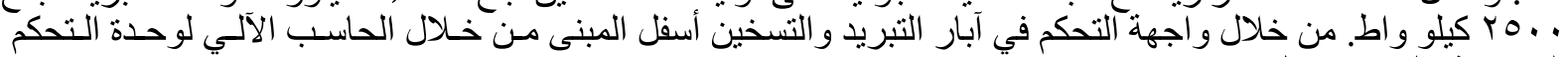

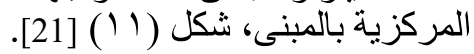

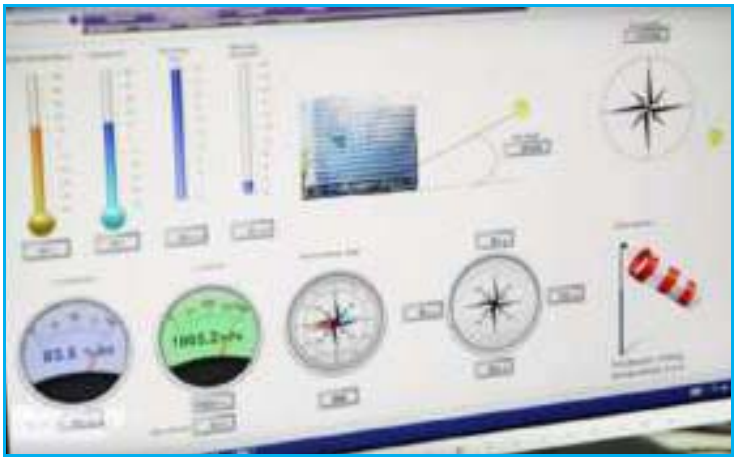

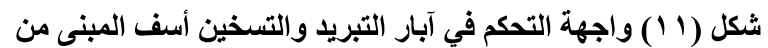

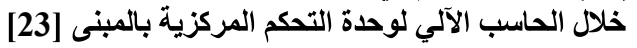

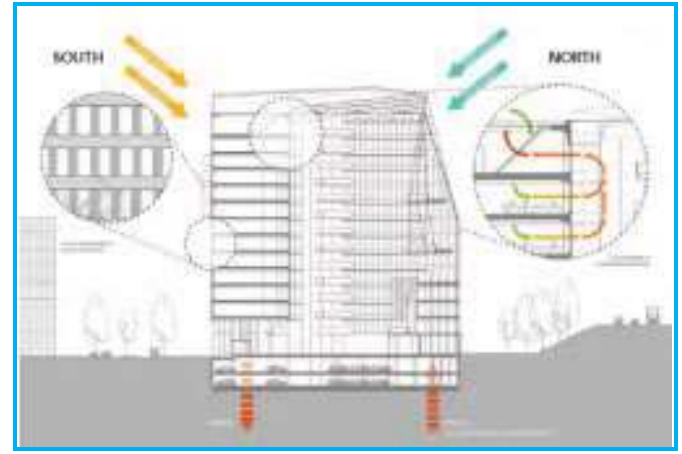

شكل (• 1 ) إدارة الطاقة بالمبنى من خلال تخزين المياه الباردة

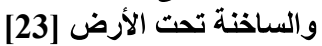

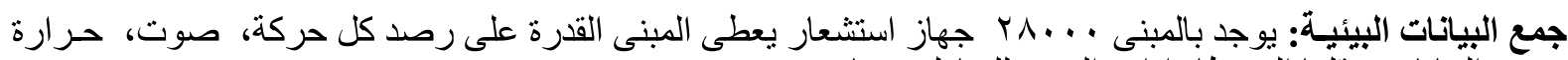
وجمع البيانات ونقلآها الى نظام إدارة المبنى للتعامل معها [25].

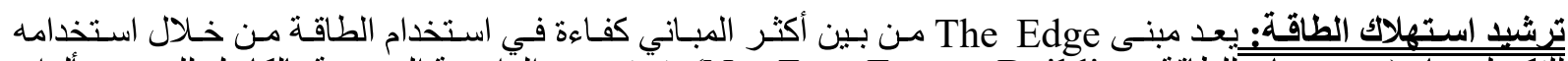

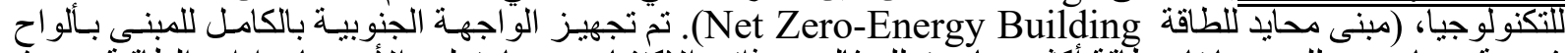

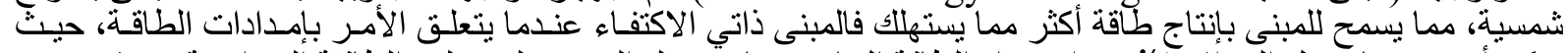

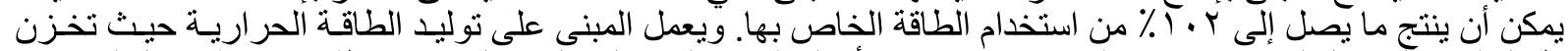

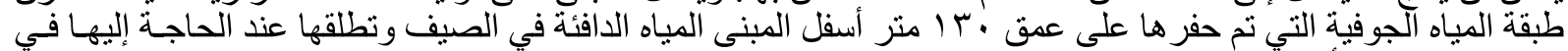
الثتاء. تم تركيب أكثر من • 1 1 عداد طاقة بالمبنى، مع تغذية جيع البيانات إلى نظّام إدارة المبنى [22].

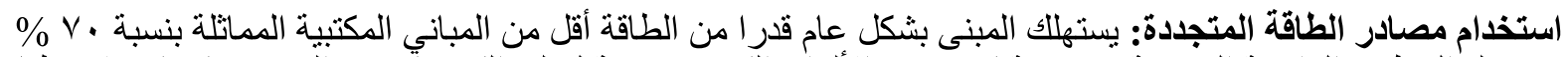

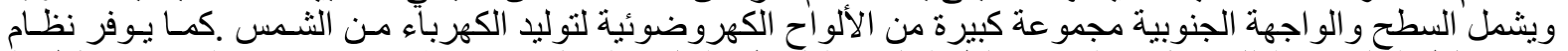

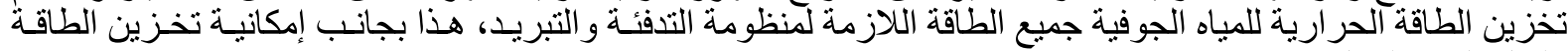

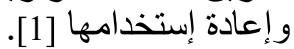

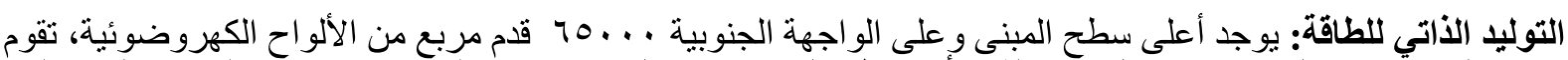

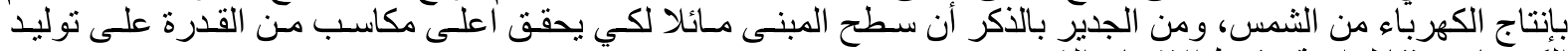
الكهرباء، وفقا لزاء اوية سقوط الإشعاع الثُمس.

\section{قد سيق تقييم المبني باستخدام "دليل المبنى الذكي IBI" :}

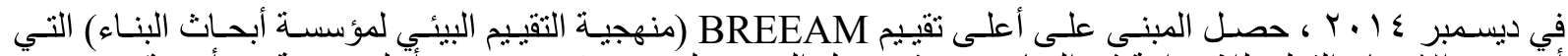

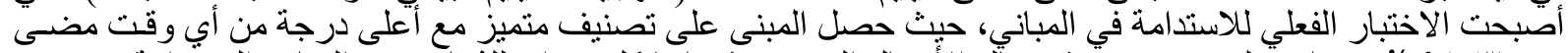

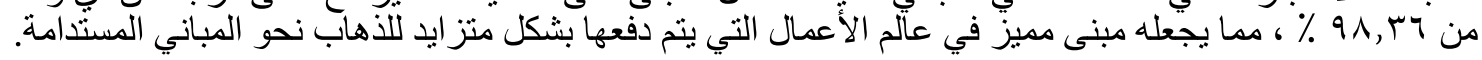

الاتتيجة: تقييم المبنى من خلال سمات الذكاء: التي تحتوي على (الأتمته ـ الاستجابة ـ التوافق مع البيئة والاستـامة) يتضح

الأتمنة المتو اجدة في المبنـي تصل الى درجة كبيـرة مـن الذكاء، نظـرًا لتـوفر معظم أنظمـة إدارة المبنـى المتكاملـة وأنظمـة الاتصالات المتقدمة الكاملة.

الاستجابة في المبنى: الاستجابة للتغيرات البيئية كاملة وعالية جدًا، وقدرة المبنى على التعلم (الاستجابة الذكية).

يمتلك المبنى التو افق مع البيئة و الاستدامة بدرجات عالية من خلال تحقيق كفاءة البيئة الداخلية و إمكانيـة قدرة المبنى لجمع البيانات البيئية وتوليد الطاقة. 


\section{الامج والتكامل بين التكنولوجيا والبيئة ( متوفرة بالمبنى)}

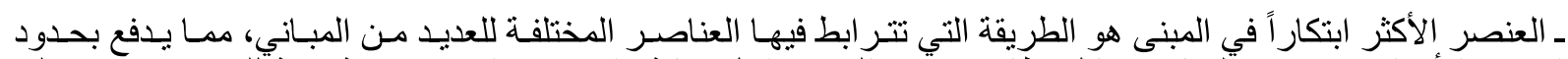

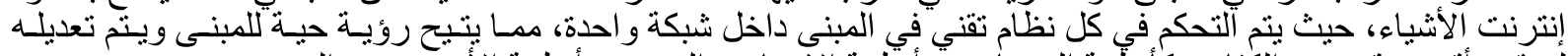

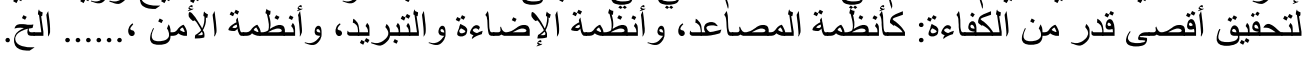

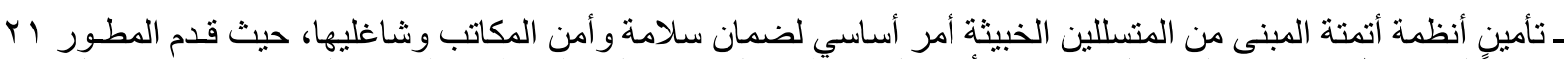

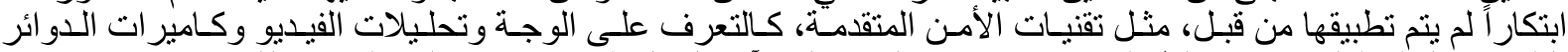
التلفيزيونية المغلقة باستخدام الطاقة عبر الايثرنت والبلاستيك الآمن لعزل الكابلات غير السامة في حالة نشوب حريق.

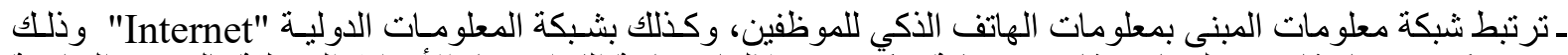

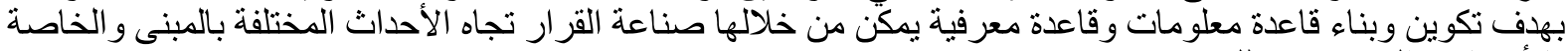
بالأشخاص المستخدمين للمبنى.

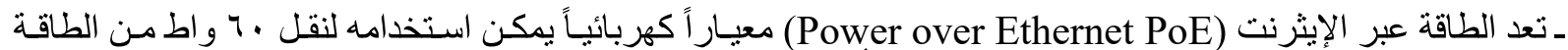

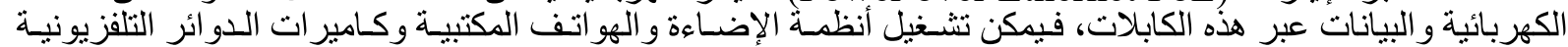

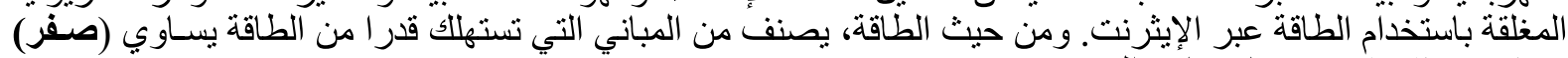

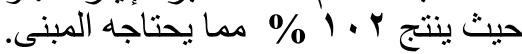

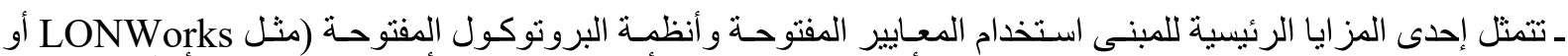

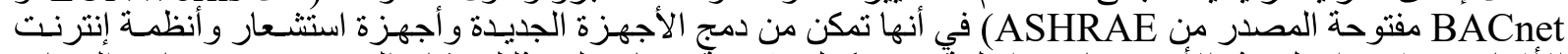

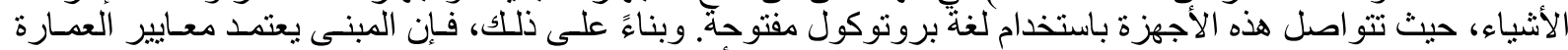
المفتوحة هو "فعال في المستقبل" ، حيث يمكن تثبيت الوظائف والأجهزة الجديدة بسهولة عند تطوير التقنيات.

ـ ربط وحدات HVAC بأنظمة الإضـاءة المكتبية الثـبكية المـزودة بكاشـفات الحركـة لإرسـال معلومـات إلى نظـام التدفئة و التهوية وتكييف الهو اء (HVAC) بحيث لا تعمل إلا عند نقطة الضبط العادية عند إثغال المبنى.

\section{آ/ آ/ مشروع المبنى الإداري لشركة فودافون بالقرية الذكية}

وصف المبنى: يقع المبنى بالقرية الذكية الو اقعة على طريق مصر اسكندرية الصحر اوي حيث سميت بهذا الاسم للدعمها

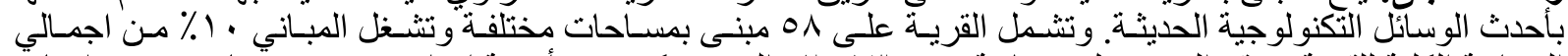

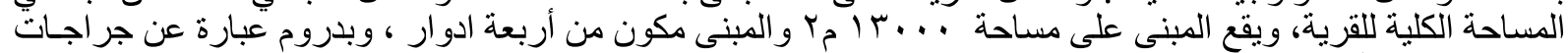

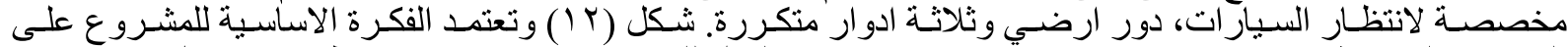

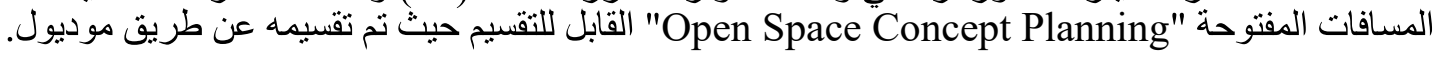

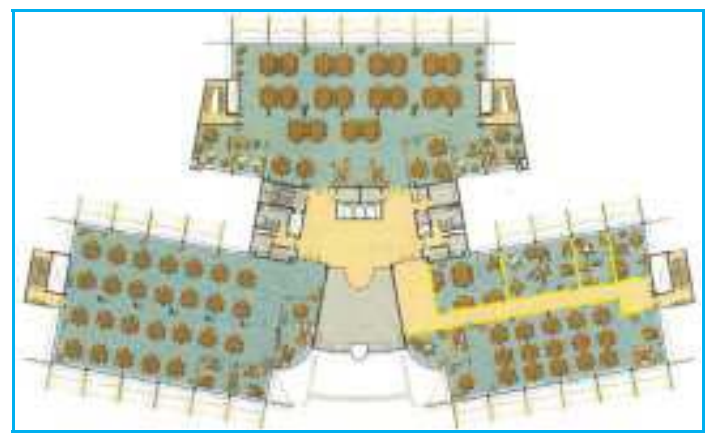

مسقط افقي للدور المتكرر

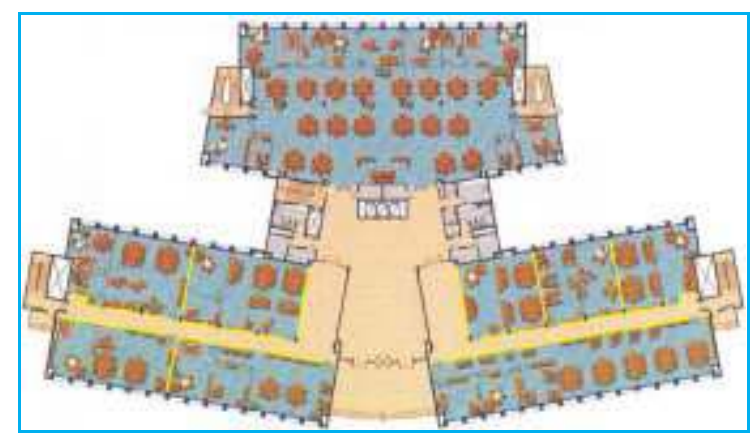

مسقط افقي للاور الارضي

شكل ( r I ) المساقط الاققية لمبنى شركة فودافون [29] 


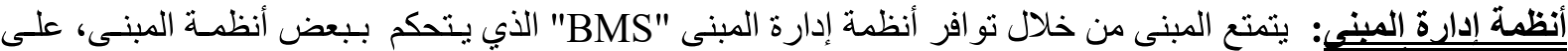

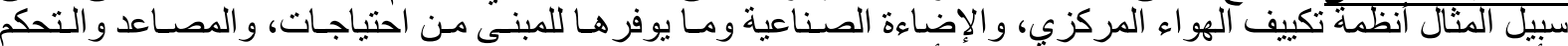

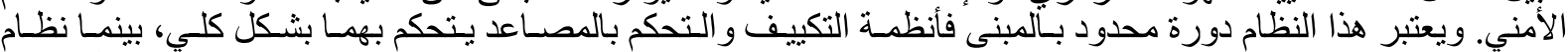

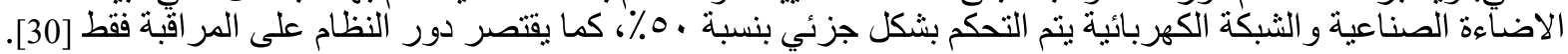

\section{أنظمة الاتصالات و الأتمتة المكتبية:}

ـ خدمة الأتمتة المكتبية عالية المستوى عن طريق شبكات حاسب آلي محلية تربط جميع الأجهزة كخدمات الفـاكس و البريد

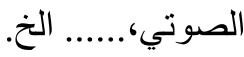

Network Printer - بيانات خادم الشبكة (Data Service) داخل المكاتب وسائل متعددة الوسـائط لكل فر درد مثنل أنظمـة

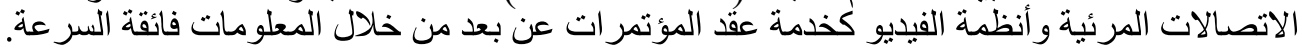
ـ حماية المشرو الإذاعة بأنظمة مانعة للصو اعق تحمي أنظمة الحاسب الآلي الضخمة وتزويد المبنى بأحدث البو ابـات الالكثرونيـة

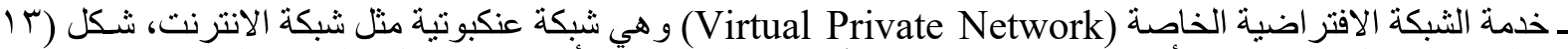
) و التي تقوم بنقل البيانات بين أكثر من اثنان مع الاحتفاظ بسرية المعلومات و أمنها، و هي اقل تكلفة من الثبكات الاخرى.

ـ فيديو قاعة المؤتمرات ل Vidio Conference

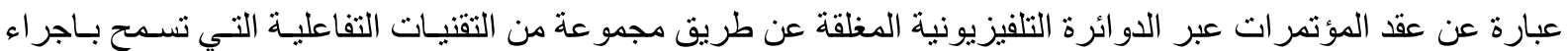

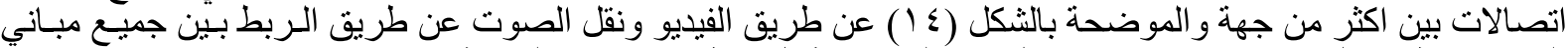
الموقع بكافة مشغلي خدمات الاتصالات و البيانات للاستجابة الفورية لاحتياجات الثن الثركة [31].

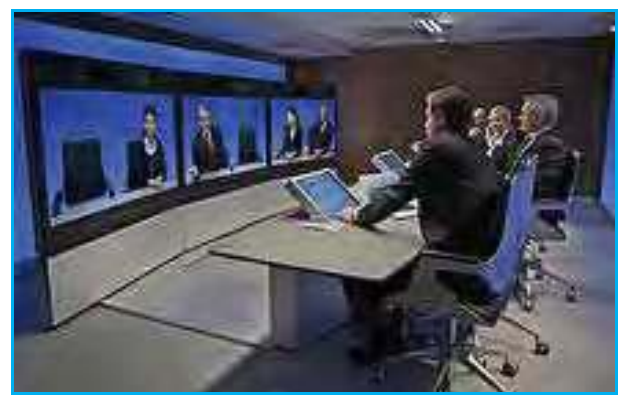

شكل (ع 1 ) عقد المؤتمرات من خلال القاعات الالكترونية [29]

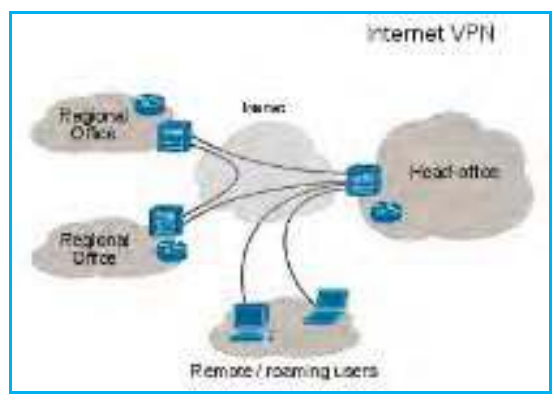

شكل (r I ا ) الشبكة الافتر اضية الخاصة [29]

ـ شبكة انترنت فائقة السر عة مع وجود أنظمة أمنية لأجهزة الحاسب الآلي للحماية من الفيروسات و الدواخل الغير قانونية.

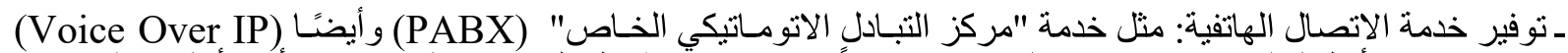

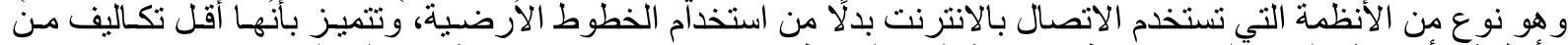

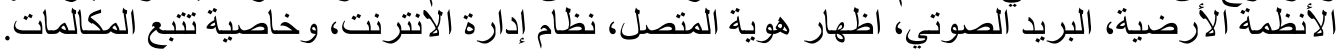

الاستجابة: لا يمتلك المبنى الاستجابة للتغيـر ات البيئيـة الداخليـة و الخارجيـة إلا في نطـاق محدود وذلك لآن أغلب أنظمـة التحكم في المبنى غير مؤتمته.

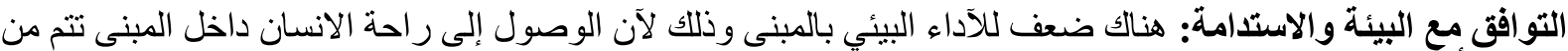

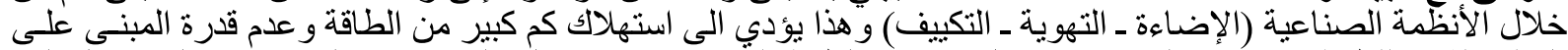

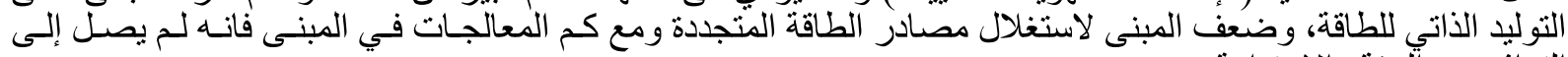

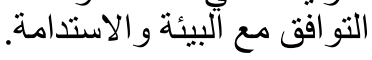




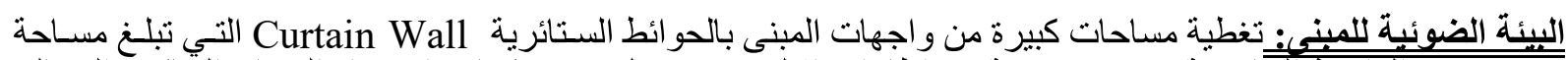

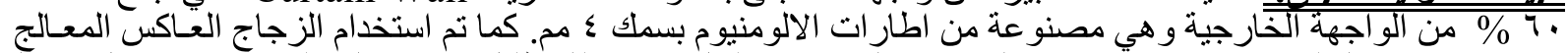

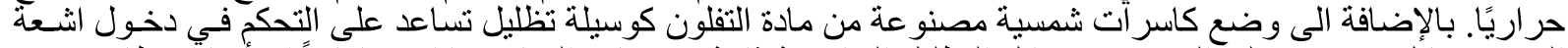
الثمس. شكل (10) =و على اللر غم من وسائل التظليل الخارجية ثابتة و لا يمكن التحكم بها اوتوماتيكياً إلا أنها آستطاعت رفع كفاءة البيئة الضوئية.
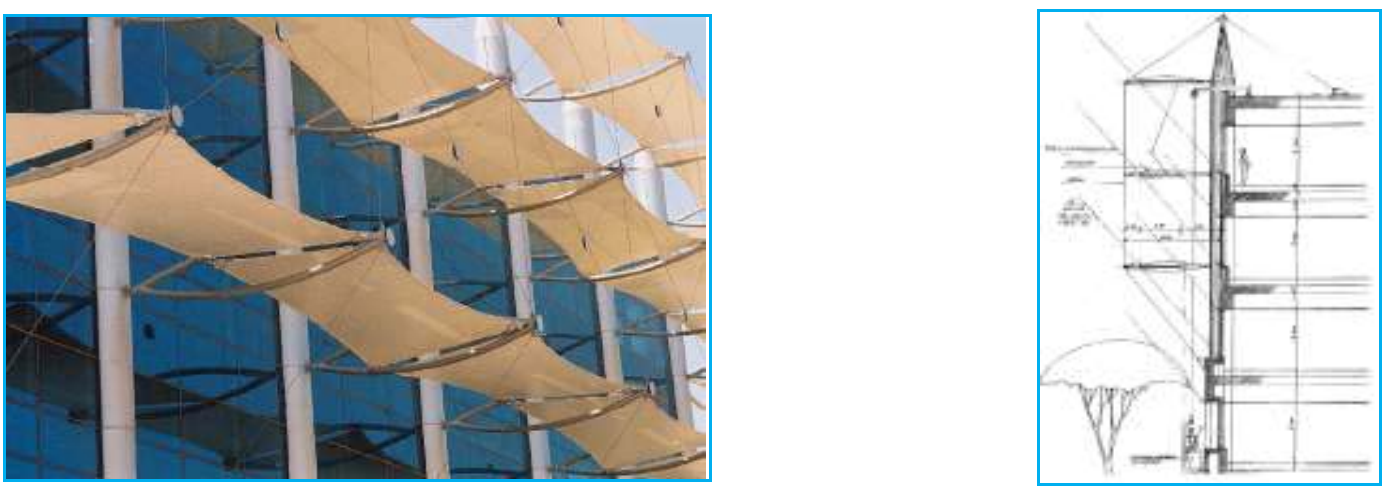

شكل ( 10 ) استخدام الكاسرات الشمسية المصنوعة من مادة التفلون [8]

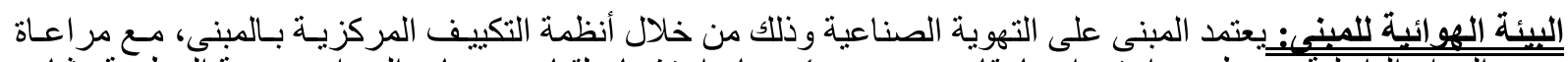

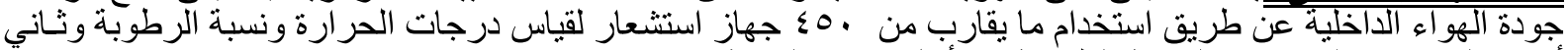
أكسيد الكربون. ولم ير اعى التهوية الطبيعية من أجل تحقيق الراحة.

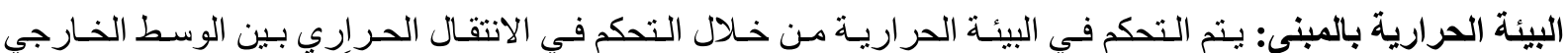

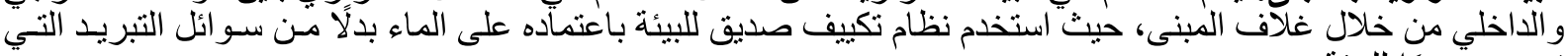
تسبب ضررًا للبيئة.

ـ جمع البيانات البيئة: يتميز المبنى باحنو ائه على مـا يقارب مـن ( • ع ) خلايـا استشعار لقياس درجـة الحـرارة ونسبة ثاني أكسيد ألكربون بالهيز الهواء.

ـ استخدام مصادر الطاقة المتجددة: على الرغم من استغلال المبنى للطاقة الثمسية الا انه لا يحقق مبدأ الاستدامة لاعتمـاده

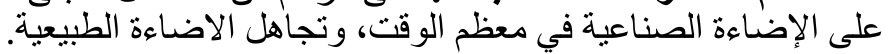

ـ التوليد الذاتي للطاقة: لا يتمتع المبنى بالتوليد الذاتي للطاقـة وربمـا يرجـع ذلك الـى ارتفـاع تكلفـة التجهيز ات و المعدات

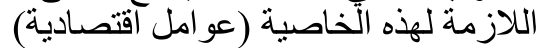

ـ ترشيد استهلاك الطاقة: هنالك در اسات بيئية ومناخية تدل على أن هنالك مخططات لترشيد استهلاك الطاقة بمبـاني القريـة،

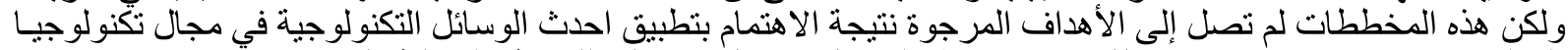
المعلومات و الاتصالات دون محاولة الاستفادة بهذه الوسائل وكيفية استغلالها للحفاظ على الطاقة وترشيد آستهلاكها.

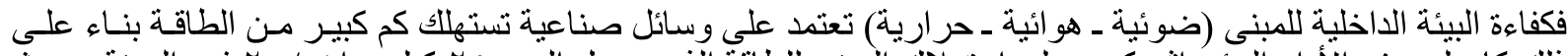

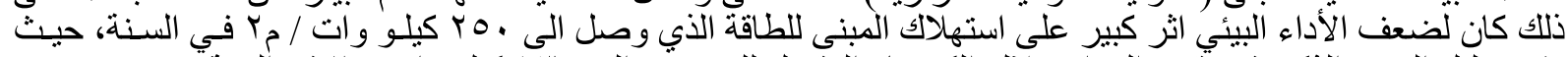

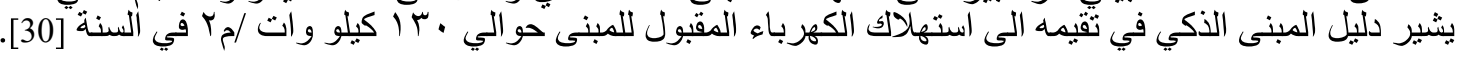

\section{قـ سيق تقييم المبنى باستخدام "دليل المبنى الذكي IBI"}

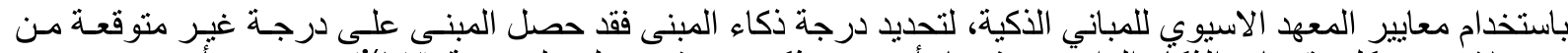

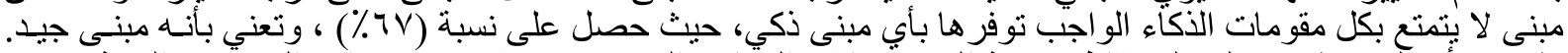

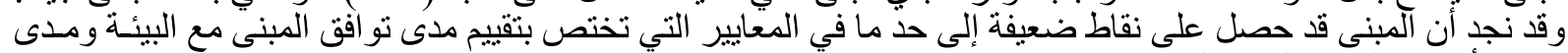
تحقيق أهداف الكبنى الذكي المستدام [8].

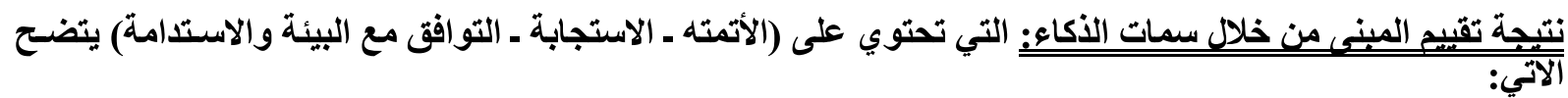


• الأتمتة المتو اجدة في المبنى تصل الـى درجـة كبيرة، نظـرًا لتوفر معظم أنظمـة إدارة المبنى وأنظمـة الاتصـالات المتقدمة الكاملة المبنة

• الاستجابة في المبنى محدودة لعدم الاستجابة للتغير ات البيئية كاملة، و عدم قدرة المبنى على التعلم (الاستجابة الذكية)

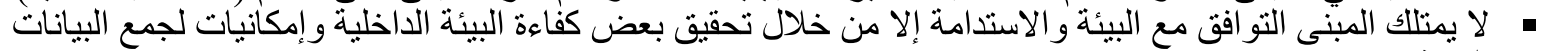

\section{الامج بين التكنولوجيا والبيئة (غير متوفرة بالمبنى)}

ـ يعتمد المبنى على التهوية الصناعية وتجاهل تام للتهوية الطبيعية ، فاهتم بالتطور التكنولوجي وتجاهل العامل البهائئي.

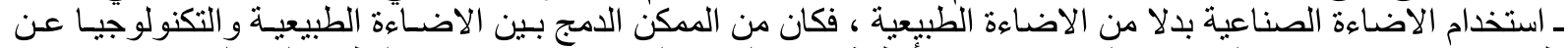

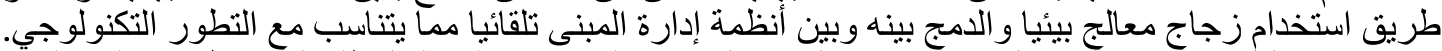

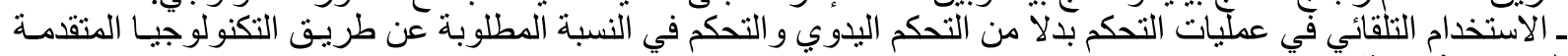
المستخدمة حديثا.

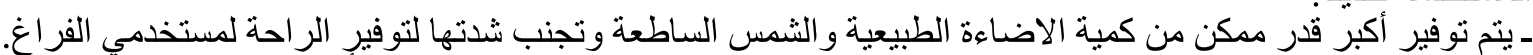

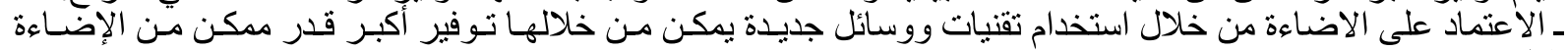

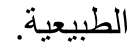

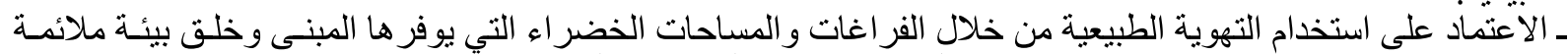

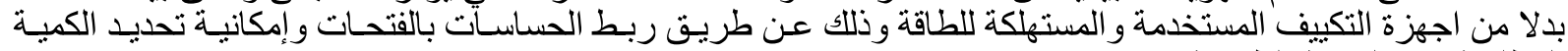
ألمطلوبة من التهوية الطبيعية.

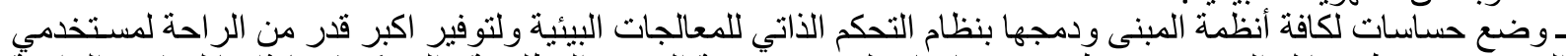

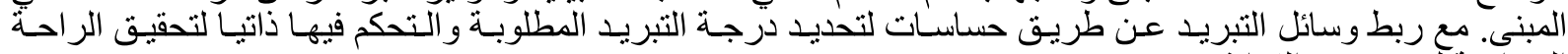

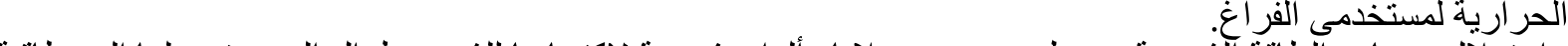

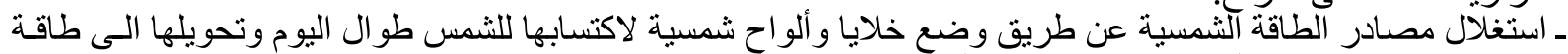

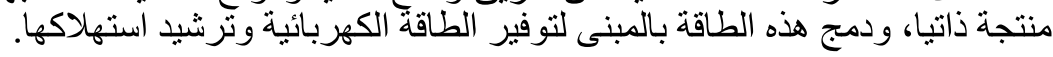

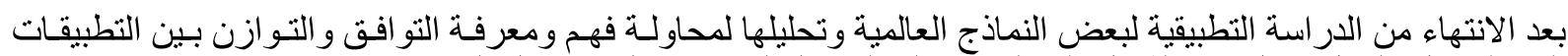

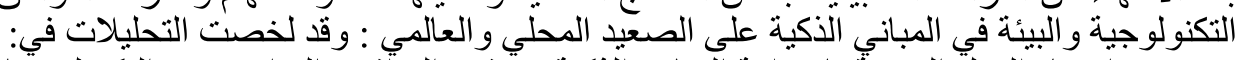

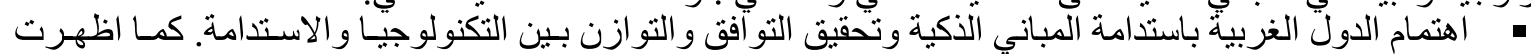

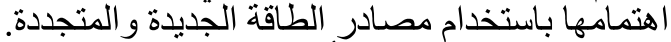

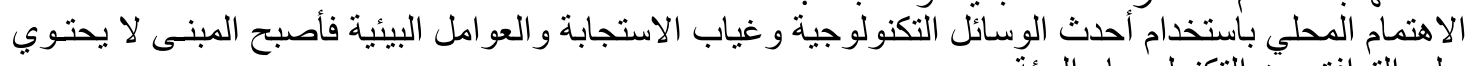
على التو افق بين التكنولوجيا و البيئة.

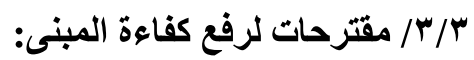
ومن هنا وجب وضع مقترح لتحسين من عملية توافق المبنى مع البيئة واستدامتها للوصول السى مبنى ذكي ومستدام ، وذللك لخلق التوازن بين التكنولوجيا و البيئة.

جدول (ץ) مقترح لمبنى شركة فودافون عن طريق دمج التقتيات الذكية ميع البيئة

\begin{tabular}{|c|c|}
\hline تطبيق المعايير التكنولوجية والبيئة على المبنى بالقرية الأكية & لمبنى شركة فودافونَّ بالقرية \\
\hline \multicolumn{2}{|l|}{ اولاً: المساقط الاققية للمبني } \\
\hline ـ استخدام القتيات واسنظمة للتأكد من الهوية عن طريق البطاقات الثخصية الرقمية . & 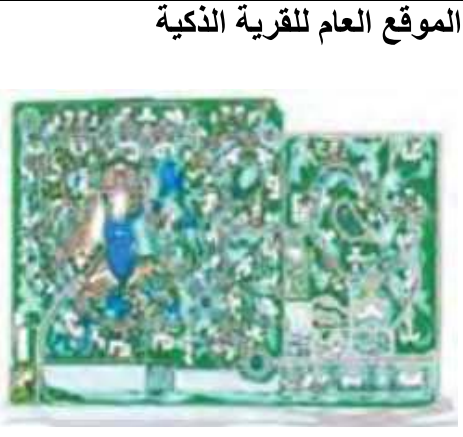 \\
\hline
\end{tabular}


فاي WI FI لفتح فيديو يسمح بمعرفـة الزوار أو التو اصـل مـع شـاغلي المبنـى مـع إمكانيـة

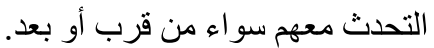

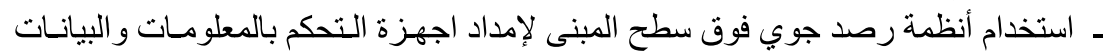

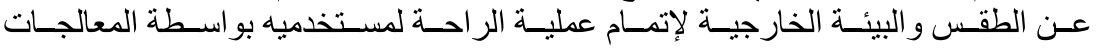

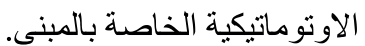
ـ التحكم في جميع تجهيز ات المبنى من خلال الثبكة و المتصـلة بالحاسب الآلي أو بالهاتف

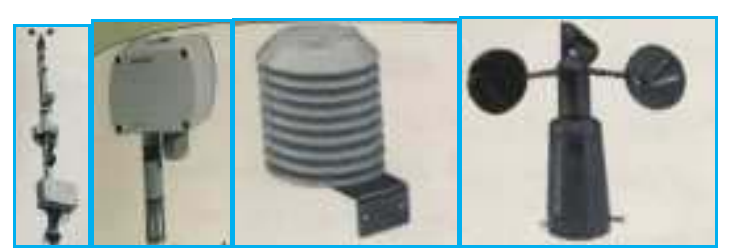
الذكي. محطات لرصد التغير ات البيئية [29]

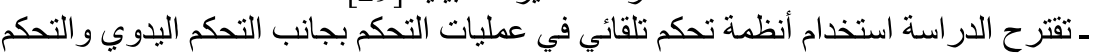
في النسبة المطلوبة عن طريق التقنيات المتقدمة المستخدمة في المبنى.

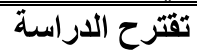

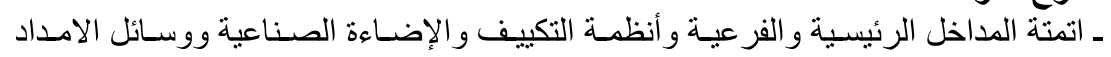

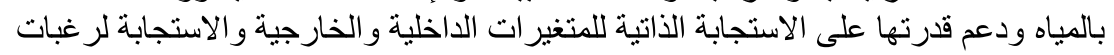

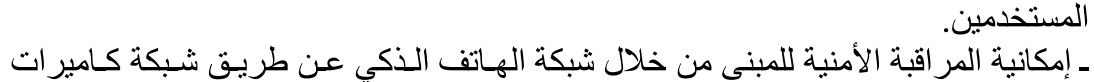

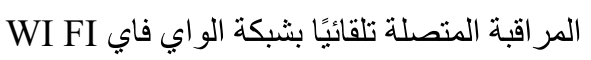

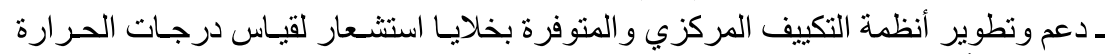

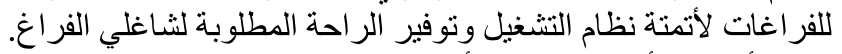

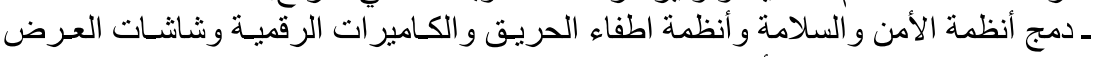
الرقمية بشكل متكامل مع الأنظمة الحالية. ـ ـ وضع وحدات الكثف عن الهوية الرقمية عند المداخل الرئيسية والفرعية.

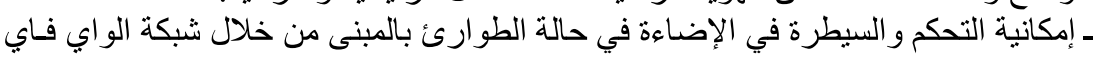

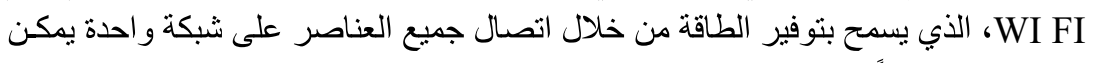
التحكم بها لاسلكياً. ـ الفصل بين الفر اغات الادارية عن طريق حاجز راسي ثابت او مـرن يمكن اتمتـة حركته

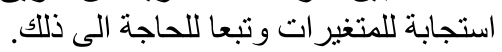

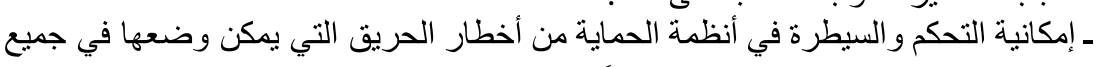

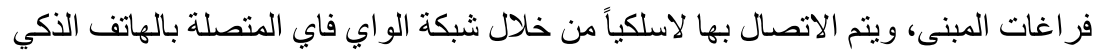

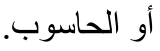

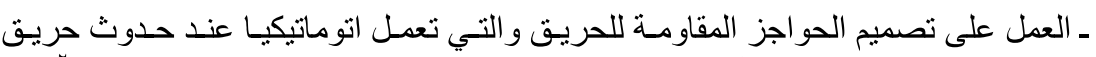

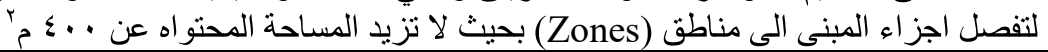

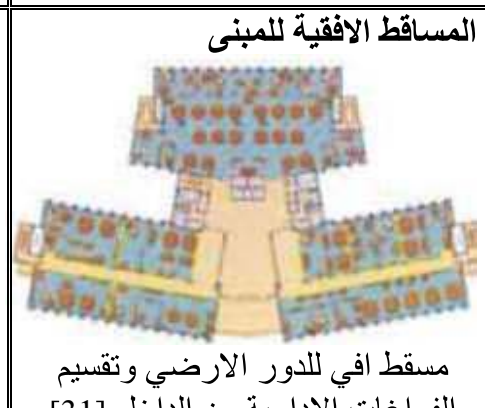

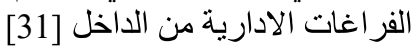

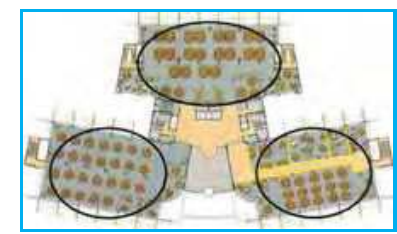

تقسيح المبنى الى مناطق (Zones) [29] ثانياً: الواجهات الخارجية للمبنى

تقترح الاراسة

- إمكانية فتح أو غلق الأبو اب بدون مفتاح، وذللك من خلال أنظمة الاتصالات اللاسلكية.

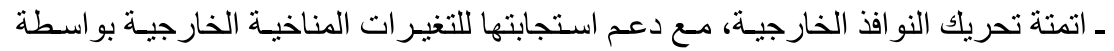

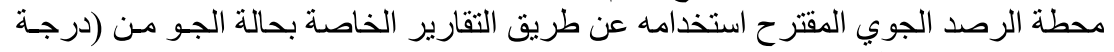

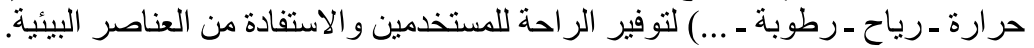

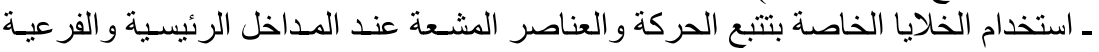
لتجنب الملوثات البيئية.

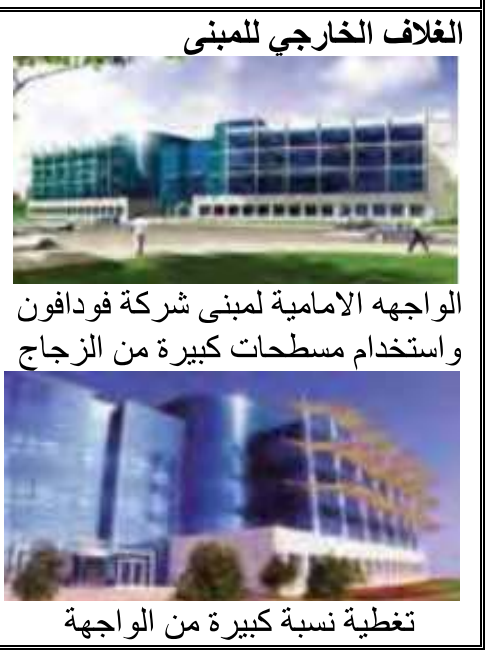




\begin{tabular}{|c|c|}
\hline 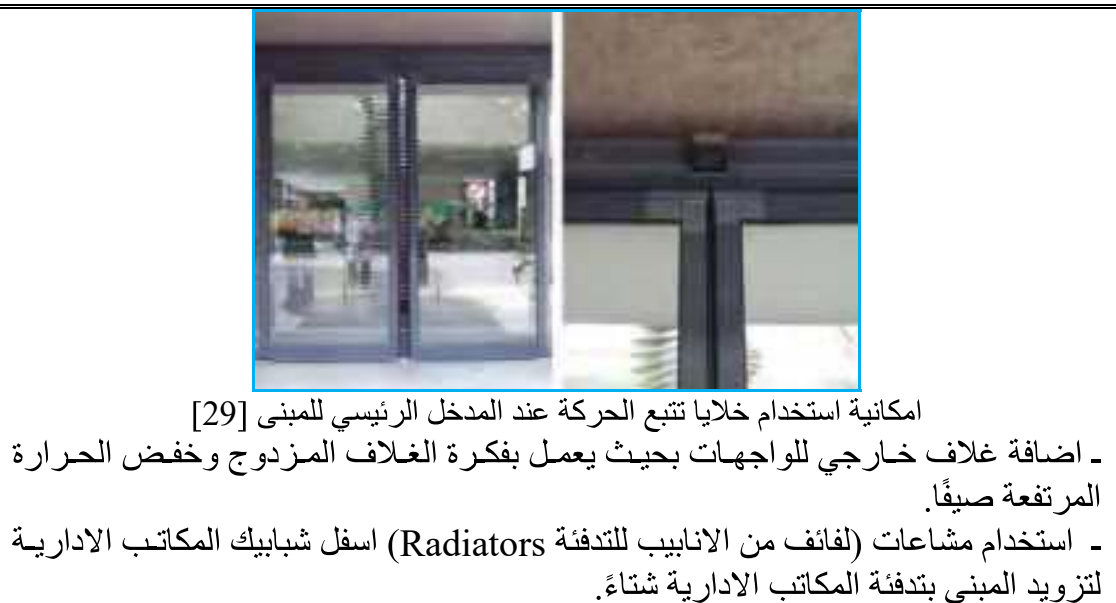 & بالحو ائد \\
\hline ثاثلًا: وسائل التظليل الخارجية للمبنة & \\
\hline 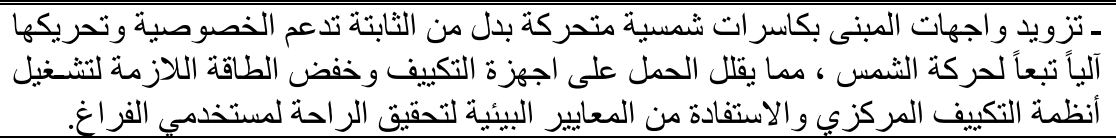 & الكاسرات الشمسية \\
\hline 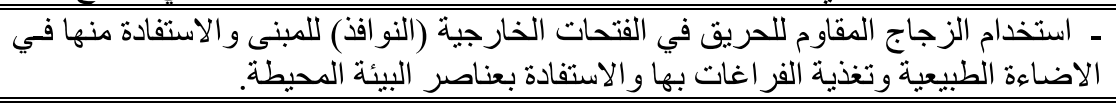 & الحوانط الستائرية \\
\hline رابعًا: مواد التشطيات الداخلية والخارجية للمبنى & \\
\hline 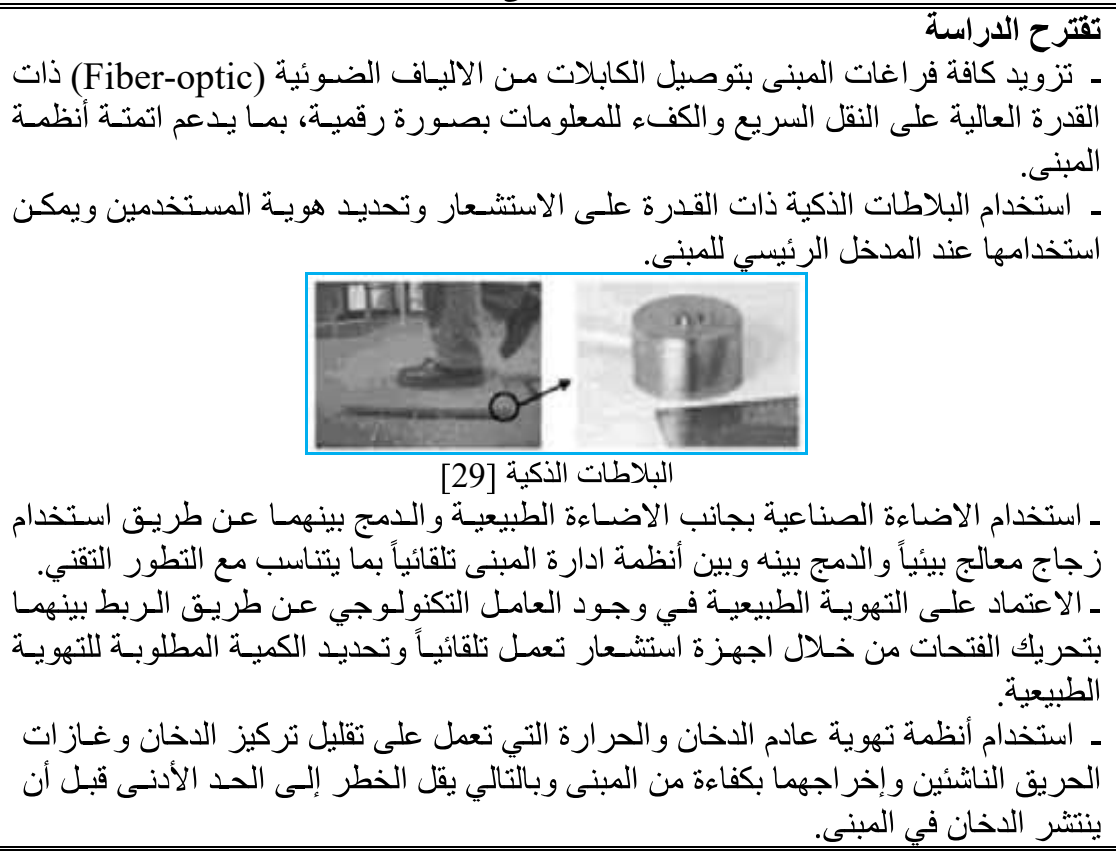 & مواد التشطيبات الداخلية" \\
\hline 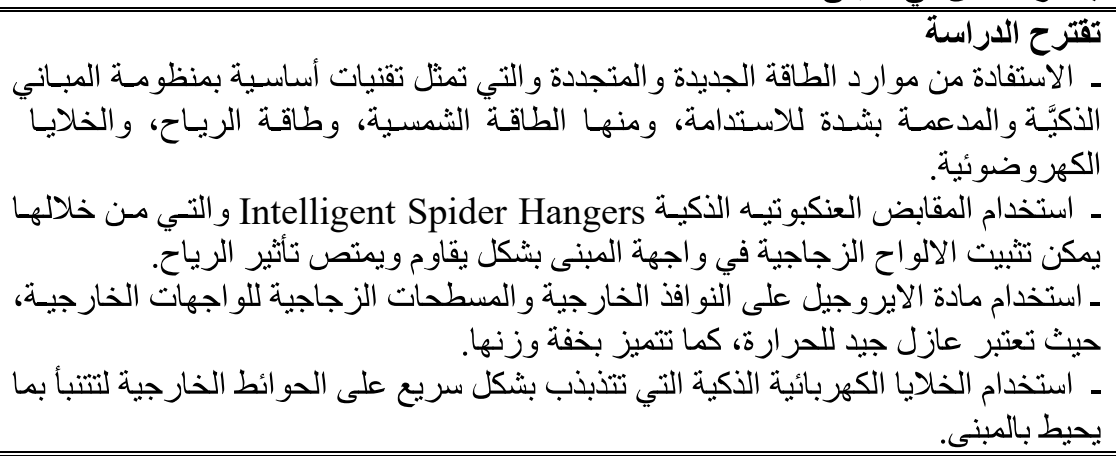 & مواد التشطيبات الخارجية \\
\hline
\end{tabular}

The Result of Analytical Study 


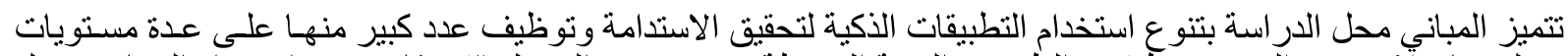

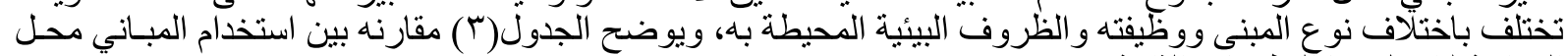
الدر اسة لتكنولوجيا التطبيقات الذكية.

جدول (r) مقارنة بين استخدام المباني محل الدراسة للتطبيقات الذكية (كجدول تقييمي)

\begin{tabular}{|c|c|c|c|}
\hline \multicolumn{4}{|c|}{ استخدام التطبيقات الذكية بالامثلة } \\
\hline 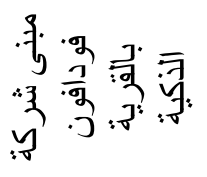 & 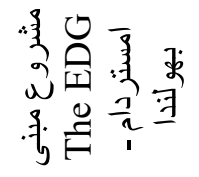 & تطبيقات التكنولوجيا الأكية & \\
\hline$\sqrt{ }$ & $\sqrt{ }$ & انظمة ادارة المبنى & \multirow{6}{*}{ 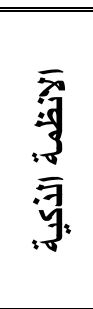 } \\
\hline$\sqrt{ }$ & $\sqrt{ }$ & انظمة الامن و الامان & \\
\hline$\sqrt{ }$ & $\sqrt{ }$ & انظمة التحكم في ادارة لطاقة & \\
\hline$\sqrt{ }$ & $\sqrt{ }$ & انظمة التحكم في عناصر المناخ & \\
\hline$\sqrt{ }$ & $\sqrt{ }$ & الانظمة الذكية للتحكم في الاضاءة & \\
\hline$\sqrt{ }$ & $\sqrt{ }$ & انظمة الاتصالات" & \\
\hline$\sqrt{1}$ & $\sqrt{1}$ & اضاءة & \multirow{5}{*}{$\begin{array}{l}\overline{3} \\
\overline{7} \\
\bar{y}\end{array}$} \\
\hline $\mathbf{x}$ & $\sqrt{ }$ & تنقية هو اء & \\
\hline $\mathbf{x}$ & $\sqrt{ }$ & تنقية مياه & \\
\hline $\mathbf{x}$ & $\sqrt{ }$ & طاقة شمسية & \\
\hline $\mathbf{x}$ & $\sqrt{ }$ & تخزين طاقة & \\
\hline$\sqrt{ }$ & $\sqrt{ }$ & استدامة الموقع & \multirow{5}{*}{ 势势 } \\
\hline $\mathbf{x}$ & $\sqrt{ }$ & المو اد و الموارد & \\
\hline$\sqrt{ }$ & $\sqrt{ }$ & كفاءة البيئة الداخلية & \\
\hline $\mathbf{x}$ & $\sqrt{ }$ & كفاءة المياه & \\
\hline $\mathbf{x}$ & $\sqrt{ }$ & كفاءة الطاقة & \\
\hline
\end{tabular}

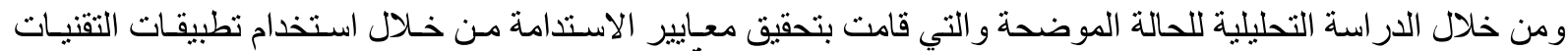

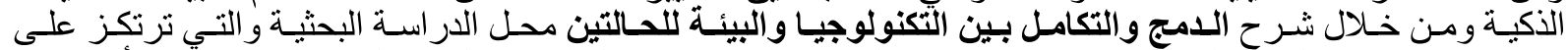

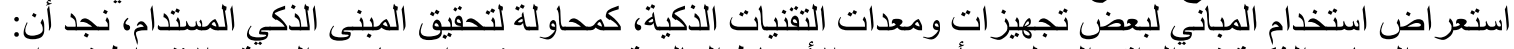

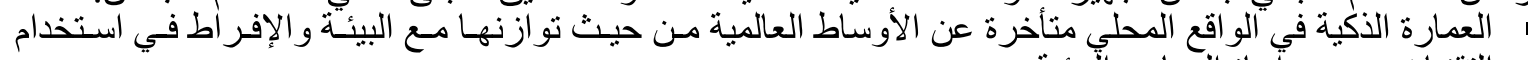

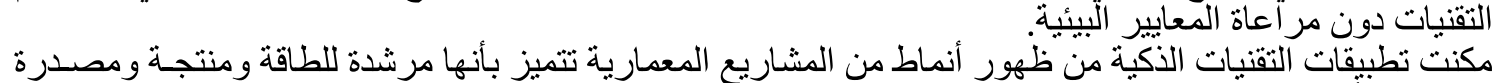

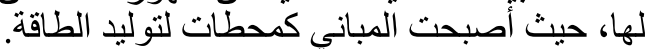

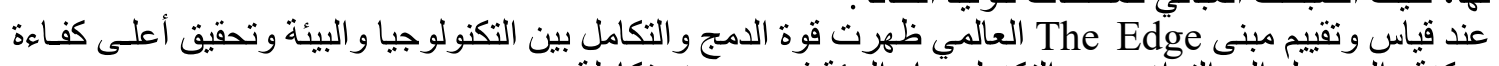

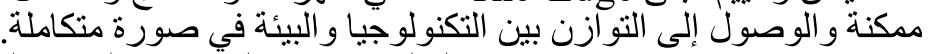

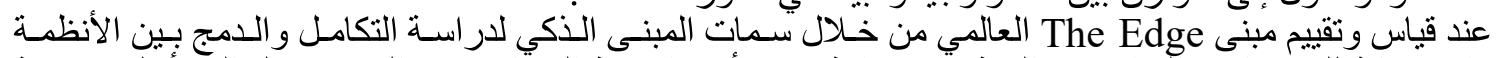

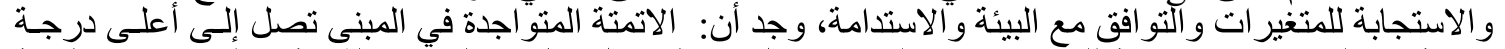

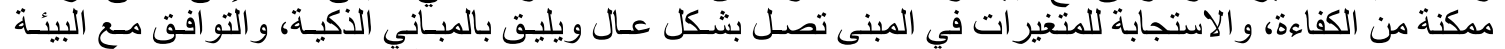

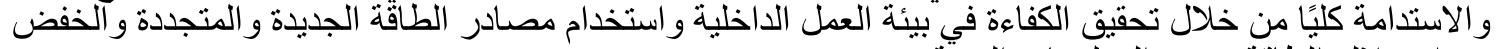

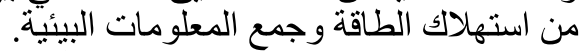

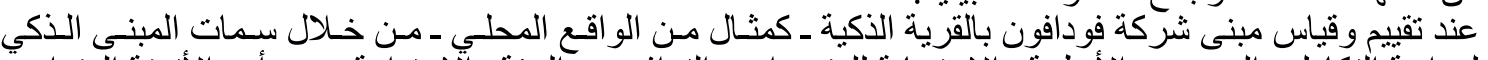

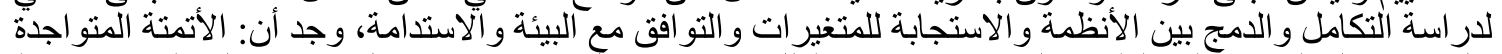

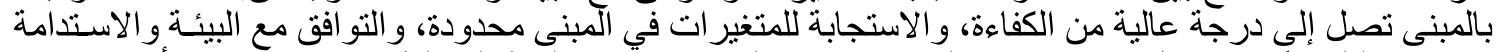
محدود وقليل جدًا من خلال تحقيق بعض المعايير كجمع البيانات وكُفاءة البيئة الداخلية ولان توجد معايير أخرى.

\section{ץ/ ع / منهجية تحقيق معايير العمارة المستدامة من خلال التطبيقات الذكية:}

يوضح الثكل التالي (1 إ) خطو ات تطبيق المنهجية المقترحة على المباني القائمة للوصول الى تقنيات المبنى الذكي الذي ير اعي الاعتبار ات البيئية المستدامة. 


\section{منهجية تطبيق التقتيات الذكية بالمباني لتحقيق الاستدامة

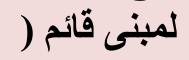

تحليل وتقييم المبنى (من خلال جدول التقييم وتحديد نقاط القوة والضعف)

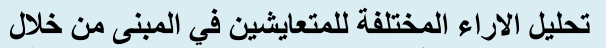
استطلاع رأي (المختصين ـ المقابلات الشخصية الشئية
دراسة مقومات الموقع والجوانب الذكية للفراغات والتجهيزات

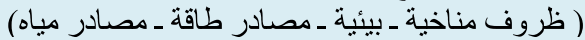

الجوانب الأكية للأنظمة والأجهزة

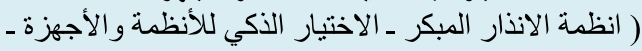

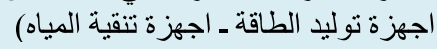

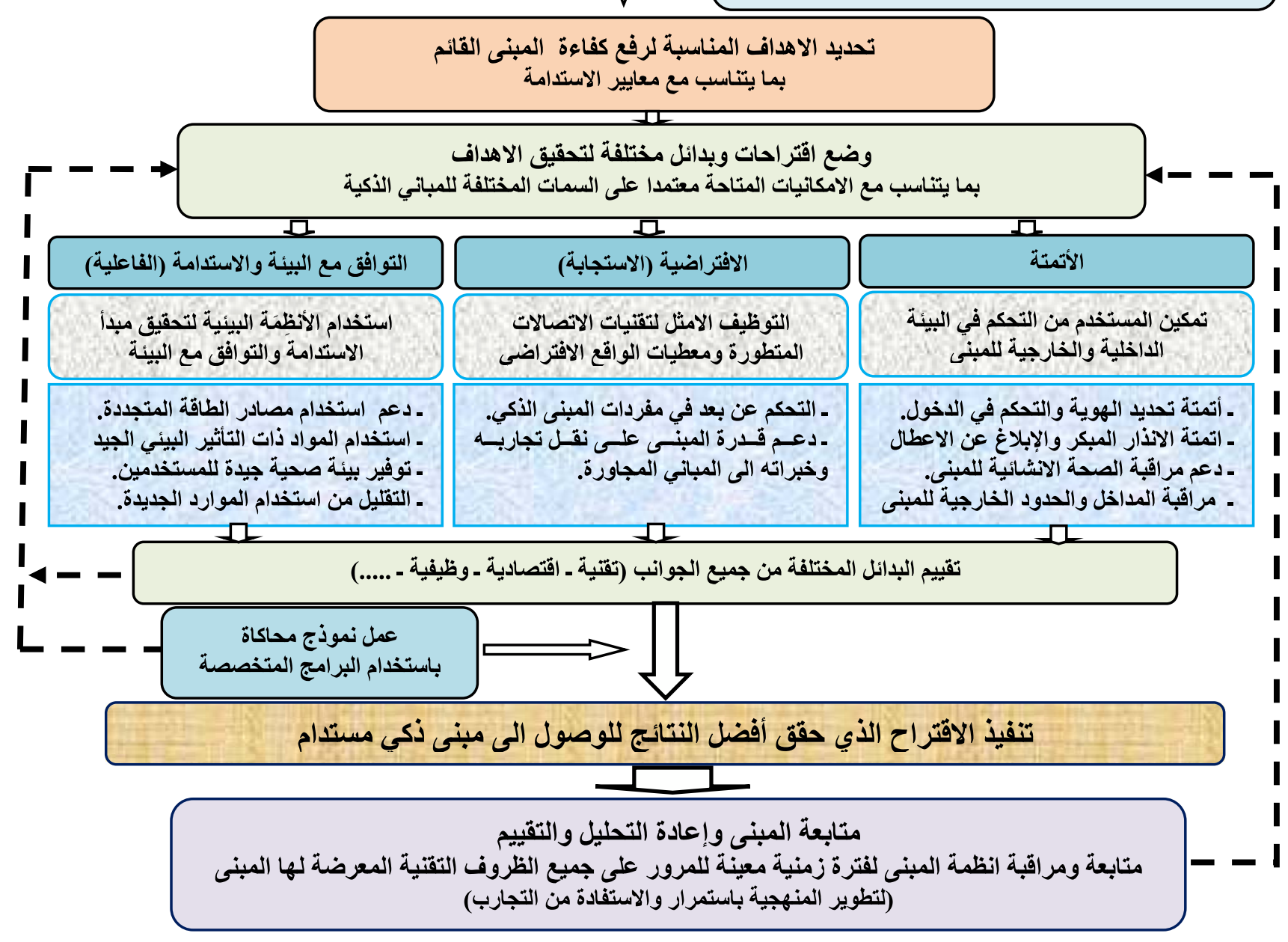

شكل (17 ) يوضح المنهجية المقترحة للمبني القائمة للوصول الى مبنى ذكي مستدام

ع النتائج والتوصيات

( - 2/ء / النتائج:

من خلال ما سبق تم التوصل إلى النتائج التالية:

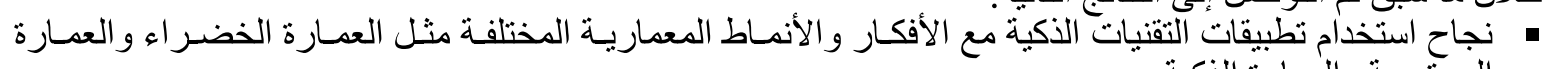

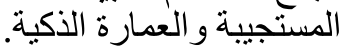

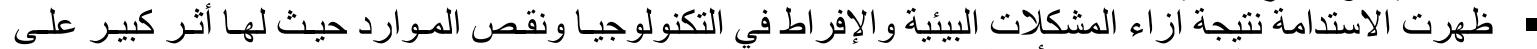

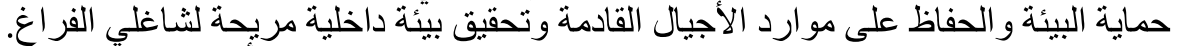

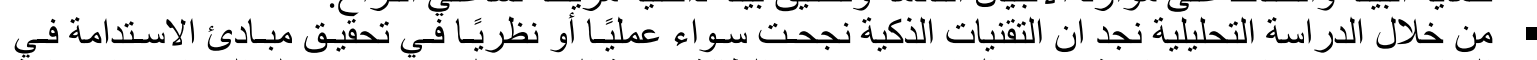

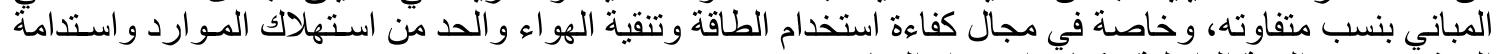

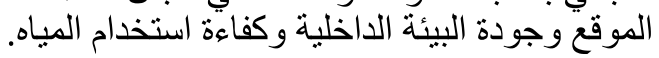




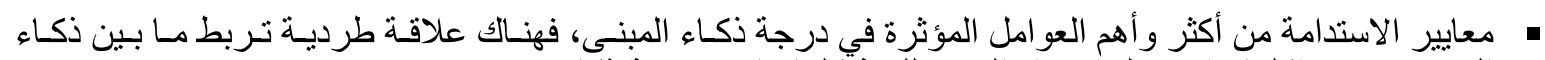

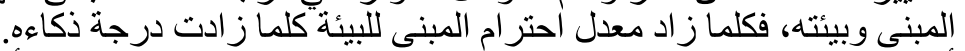

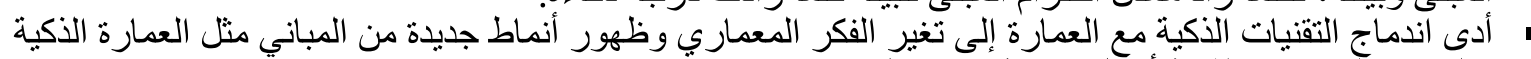

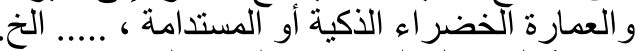

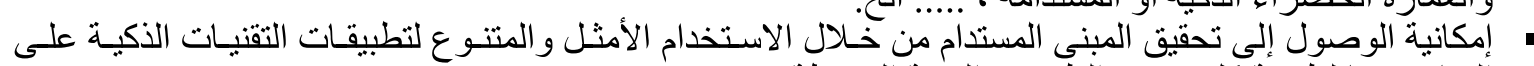

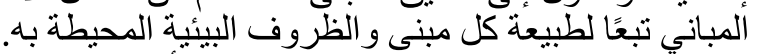

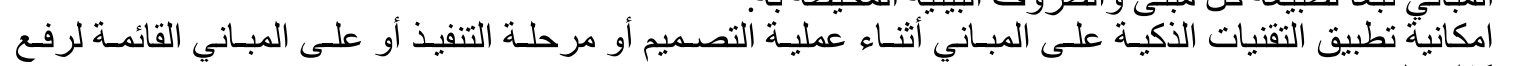
كفاءتها.

ومن أهم التوصيّات التي من شأنها الارتقاء بالمباني الذكية وتحقيق التوازن بين البيئة والتكنولوجيا، وخلق مباني مستدامة،

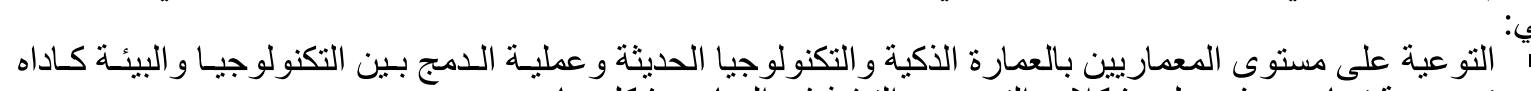

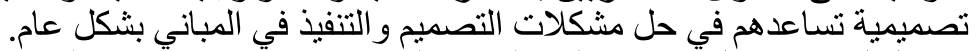

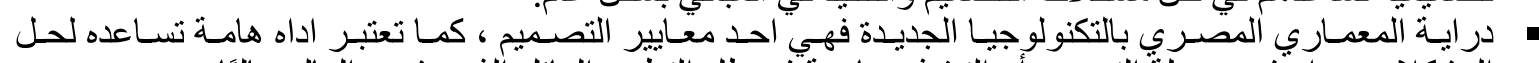

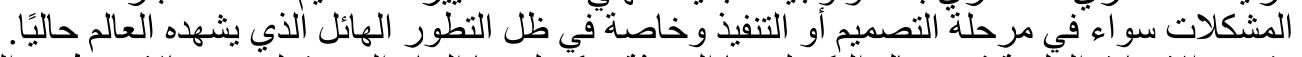

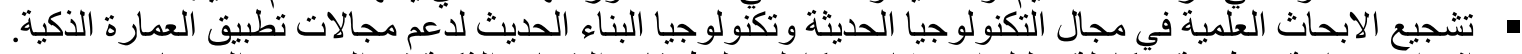

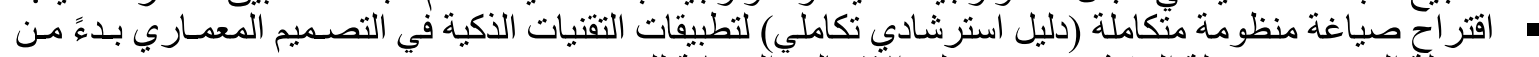

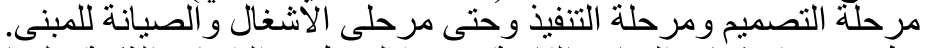

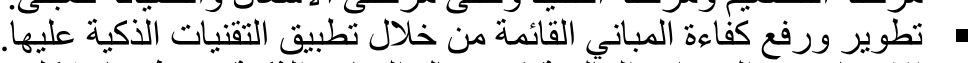

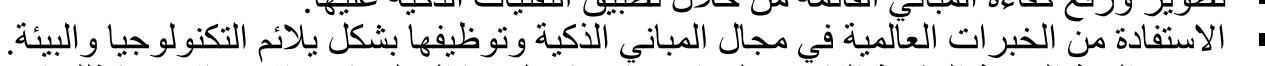

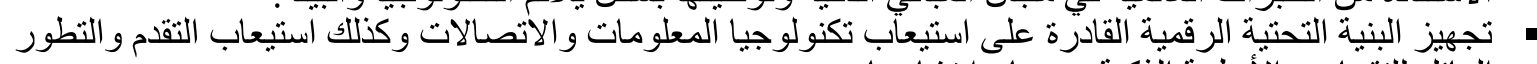

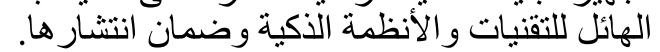

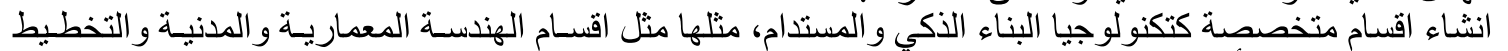

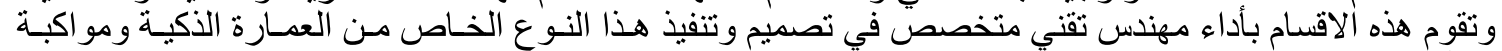

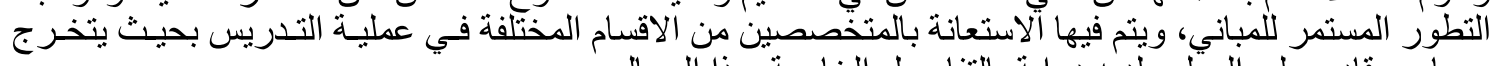

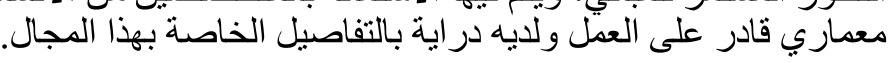

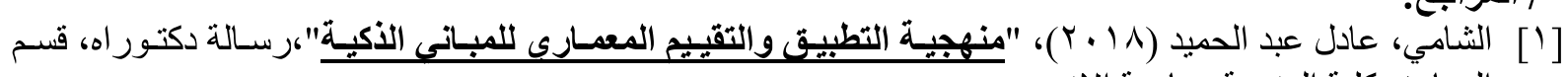

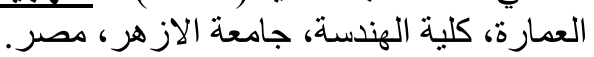

[2] Andrew Harrison, (2005). Intelligent buildings in south East Asia. Taylor \& Francis; 1 edition, $\mathrm{p} 2$.

[3] Sinopoli , Ja., (2010), " Smart Building Systems For Architects, Owners, and Builders", Elsevier Press - an Imprint of Elsevier, Kidlington, Oxford, UK .

[4] Andrew Harrison, E. L. (1998), "Intelligent Buildings In South East Asia ", E \& FN Spon, an Imprint of Routledge, New Fetter Lane, London .

[5] Elazm, F. (2017). Towards Novel and Appropriate Smart Buildings " Beijing Water Cube ". 2 Smart Architecture. International Journal of Environmental Science.

[6] Wang, Shengwei. (2010)," Intelligent Buildings and Building Automation", Spon Press - an Imprint of Taylor \& Francis Group, Oxon, USA .

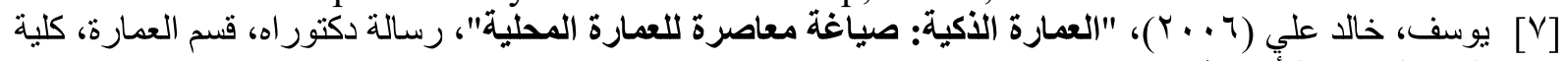

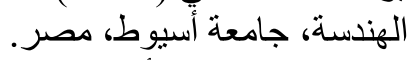

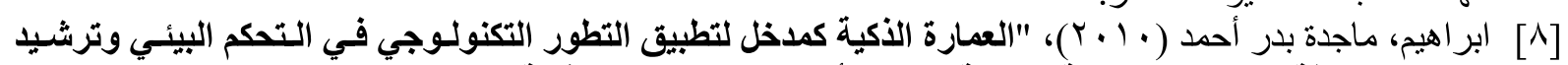

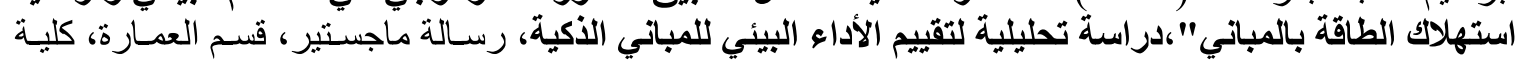

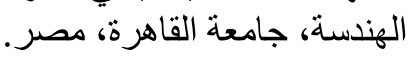

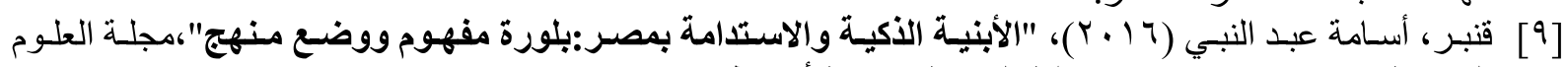

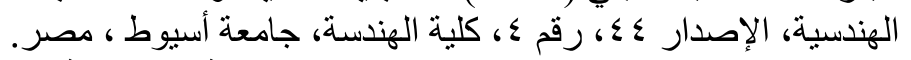

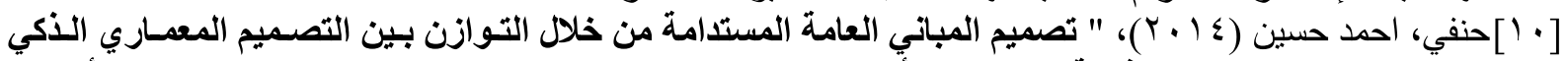

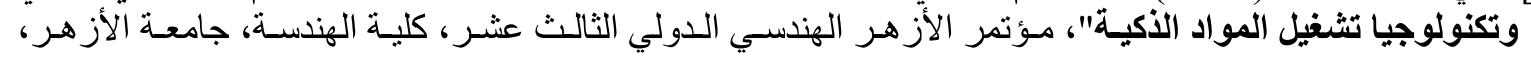

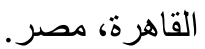

[11] Yang, C. (2018). "Smart Building Energy Systems". In R. Wang, Handbook of Energy Systems in Green Buildings. P4. 
[12] Johnny, W., (2007), "Development of Selection Evaluation and System Intelligence Analytic Models for the Intelligent Building Control Systems", $\mathrm{PhD}$, The Hong King Polytechnic University, Department of Building and Real Estate, Hong Kong.

[13] Hatley, D.D., et al. (2005) "Energy Management and Control System Desired Capabilities and Functionality", U.S. Department of Energy, Richland, Washington, USA.

[14] Strathfield Council. (2007). Building Energy - Smart Guide.

[15] Youssef Elkhayat. (2014)." Interactive Movement in Kinetic Architecture". Journal of Engineering Sciences, Assiut University, Faculty of Engineering, Vol. 42, No. 3, Pages: 816-845

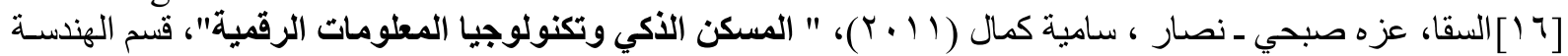

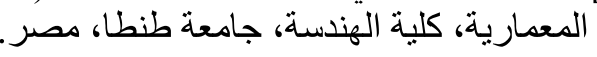

[17] Wong , J.K.W, Li, H., \& Wang ,S.W, (2005) , "Intelligent Building Research : a Review ", Department Of Building And Real Estate, The Hong Kong Polytechnic University, Hunghom,Kowloon, Hong Kong, Elsevier Press .

[18] Christiansson, Per (2000) "Knowledge Representation and Information Flow in the Intelligent Building", International Conference on Computing in Civil and Building Engineering, American Society of Civil Engineers, Reston, Virginia, USA.

[19] National Institute of Building Sciences, Whole Building Design guide, http://www.wbdg.org/design/sustainable.php

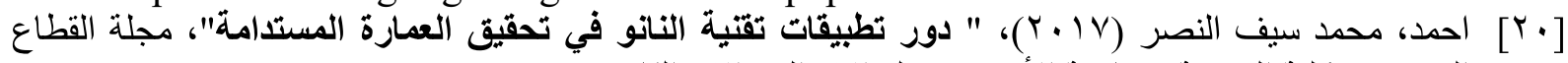

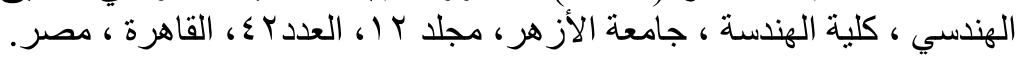

[21] https://www.bbc.com/news/technology-35746647

[22] https://www.gensbouw.nl/nl/projecten/detail/the-edge

[23] Aftab Jalia, at., al., (2018) "The Edge, Amsterdam, Showcasing an exemplary IoT building", Centre for Natural Material Innovation, Department of Architecture, University of Cambridge.

[24] http://www.buildup.eu/en/practices/cases/edge-amsterdam-office-building-highestbreeam-score-date

[25] Kleibrink, M. (2013). smart working smart buildings and the future of work. Light life.

[26] owen.king@Unwork.com

[27] www.weforum.org

[28] https://www.arubanetworks.com/en-gb/resources/deloitte-netherlands

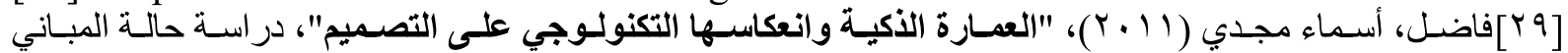

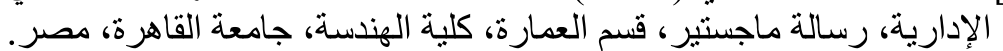

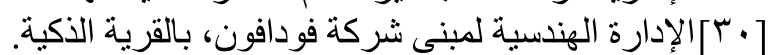

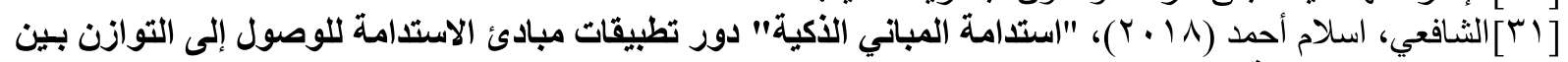

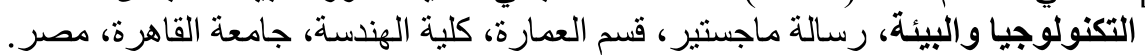

